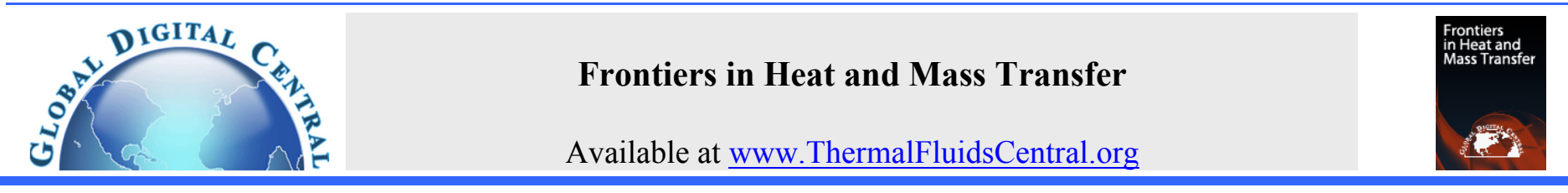

\title{
RECENT PROGRESS ON EXPERIMENTAL RESEARCH OF CRYOGENIC TRANSPORT LINE CHILLDOWN PROCESS
}

\author{
J. N. Chung ${ }^{*}$, Kun Yuan \\ Department of Mechanical and Aerospace Engineering, University of Florida \\ Gainesville, FL. 32611-6300, USA
}

\begin{abstract}
Chilldown or quenching is a complicated process that initiates the cryogenic fluid line transport, and it involves unsteady two-phase heat and mass transfer. To advance our understanding of this process, we have reviewed recent experimental investigations. The chilldown process can be generally divided into three regimes: film boiling, transition boiling and nucleate boiling, and each regime is associated with a different flow pattern and heat transfer mechanism. Under low flow rate conditions, it is concluded that the two-phase flow regime is dispersed flow in the film boiling regime. The dispersed liquid phase is in the form of long filaments as the transport line is chilled down, and the vapor phase is generally superheated. Microgravity experiment for line chilldown was conducted basically in the film boiling region. Bottom wall heat flux was found to decrease under microgravity condition. Under the experimental condition, the gravity effect does not show a strong dependence on wall temperature and inlet flow rate.

Keywords: Cryogenic chilldown, transport line, space applications.
\end{abstract}

\section{INTRODUCTION}

Cryogenic fluids are widely used in industrial applications, space exploration, and cryosurgery systems and so on. In these systems, proper transport, handling and storage of cryogenic fluids are of great importance. When a cryogenic system is first started up, its walls and hardware must go through a transient chill down period prior to reaching a steady operation. Therefore, chilldown is the process of keeping the system adjusted to the low temperature scale which is usually several hundred degrees below the room temperature. The chilldown or quenching process is complicated, involving unsteady two-phase heat and mass transfer, and has not been fully understood.

Cryogens are usually used as a liquid fuels such as liquid hydrogen and oxygen in the rocket industry, liquid nitrogen and helium are frequently used to cool superconducting magnetic device for medical applications. In some special cases, for example, cryogenic fluids are used in spacecrafts not only at low temperatures but also under reduced gravity. Liquid oxygen and hydrogen are used to power launch vehicles and helium is used for pressurizing fuel tanks. For these applications, the transport and storage of cryogenic fluids under microgravity is regarded as an important element of the space mission.

Furthermore, on space exploration, efficient and safe use of cryogenic fluids in thermal management, power and propulsion, and life-support systems of a spacecraft during space missions involves transport, handling, and storage of these fluids under both terrestrial and microgravity conditions. The uncertainties about the flow regime and heat transfer characteristics pose severe design concerns. Moreover, the thermo-fluid dynamics of two-phase systems in microgravity encompass a wide range of complex phenomena that are not understood sufficiently for complete and optimal engineering design of the entire system.
Cryogenic fluids are also widely used in industrial systems. Until the early 1970s, liquid hydrogen was mainly used by NASA as a rocket fuel; however, development and growth of commercial markets have since outpaced this use. For example, liquid hydrogen is used in industrial applications such as metal processing, plate glass production, fat and oil hardening, semiconductor manufacturing, and pharmaceutical and chemical manufacturing. Today, the commercial market is many times larger than the government needs.

\subsection{Role of Cryogenics in Space Exploration}

The extension of human space exploration from a low earth orbit to a high earth orbit, then to Moon, Mars, and possibly asteroids and moons of other planets is one of NASA's biggest challenges for the new millennium. Integral to this is the effective, affordable, and reliable supply of cryogenic fluids. The efficient and safe utilization of cryogenic fluids in thermal management, power and propulsion, and life support systems of a spacecraft during space missions involves the transport, handling, and storage of these fluids in terrestrial and reduced gravity. The uncertainties about the flow pattern and heat transfer characteristics pose a severe design concern. Therefore, the design of cryogenic fluid storage and transfer system is very important and spawns research in several areas: for example, design of the vessel, the piping and draining system, insulation and safety devices. Moreover, the thermo-fluid dynamics of two-phase systems in reduced gravity encompasses a wide range of complex phenomena that are not understood sufficiently for engineering design to proceed.

Chilldown process is the inevitable initial stage during cryogenic fluid transport. Due to their low boiling points, boiling and two-phase flows 
are encountered in most of the cryogenic operations. The complexity of the problem results from the intricate interaction of the fluid dynamics and heat transfer, especially when phase-change (boiling and condensation) is involved. Because of the large stratification in densities between the liquid and vapor phases, the reduced gravity condition in space would strongly change the terrestrial flow patterns and accordingly affect the momentum and energy transport characteristics. Therefore, boiling and two-phase flow behave quite differently when the gravity levels are varied. The uncertainties about the flow pattern, pressure drop and heat transfer characteristics pose a severe design concern. For example, there is considerable disagreement over the chilldown heat fluxes and whether a unique rewetting temperature exists (Dhir et al. 1981; Piggott and Porthouse 1975). Different definitions of rewetting temperatures are reported in chilldown researches: Leidenfrost temperature, minimum film boiling temperature, quenching temperature from thermocouple observations and the temperature at which critical heat flux occurs (Dhir et al. 1981). For similar experimental observations, quiet different explanations were also suggested by different researchers. For example, it was reported that the rewetting velocity increased with increasing inlet flow rate, given the same initial wall temperature (Yamanouchi 1968, Duffey and Porthouse 1973, Thompson 1974), Duffey and Porthouse (1973) suggested that the flow rate effect resulted from increasing the wet side heat transfer coefficient with higher inlet flow. This improves the rate of axial heat conduction and hence leads to a faster rewetting rate. Thompson (1974), however, argued that the inlet flow rate affects precooling on the dry side rather than the heat transfer in the wet side. Additionally, because of the experimental difficulties, in general, there is very little heat transfer data for cryogenic flow boiling in reduced gravity. A representative work is reported by AdhamKhodaparast et al. (1995).

Another driving force of recent investigations, for example, comes from the need for further understanding of the cryogenic chilldown process under low mass flux in a thermodynamic vent system (TVS) on spacecrafts. A TVS is a system where a small amount of liquid is withdrawn from a cryogenic propellant tank and vented to remove heat from the bulk liquid cryogen in the tank and thus lower the tank pressure (Lin et al. 1991; Van Dresar et al. 2001, 2002). The mass flux in TVS system is generally very low. Systematic experiments for steady state low mass flux cryogenic two-phase flow were conducted by Van Dresar et al. (2001, 2002), the highly transient chilldown process was, however, not included.

\subsection{Background and Literature Review}

Cryogenic chilldown involves complex interaction of energy and momentum transfer among the two phases and the solid wall. Understanding of the boiling phenomenon, flow regime and heat transfer regime provides foundation for further insight into this dynamic process. The following section gives background information of boiling, two-phase flow regime and heat transfer regime. Previous experimental research that is related to cryogenic chilldown and microgravity boiling are reviewed and qualitatively assessed in the section below.

\section{Boiling Curve}

A boiling curve shows the relationship between the heat flux that the heater supplies to the boiling fluid and the heater surface temperature. According to the typical boiling curve (Figure 1), a chilldown (quenching) process usually starts from point $\mathrm{E}$, and then goes towards point $\mathrm{D}$ in the film boiling regime as the wall temperature decreases. Point $\mathrm{D}$ is called the Leidenfrost point which signifies the minimum heater temperature required for the film boiling. For the film boiling process, the wall is so hot that liquid will vaporize before reaching the heater surface which causes the heater to be always in contact with vapor. When cooling beyond the Leidenfrost point, if a constant heat flux heater was used, then the boiling would shift from film to nucleate boiling (somewhere between points A and B) directly with a substantial decrease in the wall temperature because the transition boiling is an unstable process.

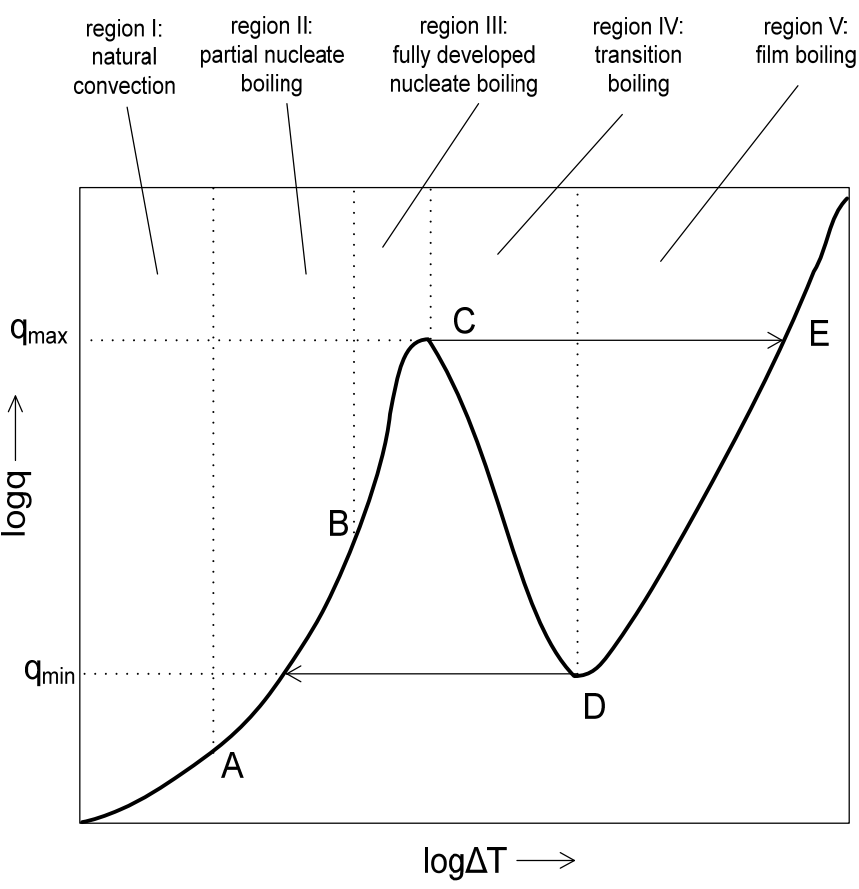

Fig. 1 Typical boiling curve.

\section{Two-Phase Flow Regimes and Heat Transfer Regimes}

The flow in cryogenic chilldown process is typically two-phase flow, because the wall temperature usually exceeds the liquid boiling temperature up to several hundred Celsius in the beginning. The topology of two-phase flow has an important effect on heat transfer and pressure drop in the flow channel. Therefore, generally the first step in two-phase flow experiment or modeling is to determine the two-phase flow regime. Commonly observed flow regimes in horizontal tubes are shown in Figure 2.

General descriptions of the two-phase flow regimes can be referred from Carey (1992) and Van Dresar and Siegwarth (2001). Flow regimes of common two-phase flow such as air-water have been extensively mapped from experiments. However, the published data for cryogens are limited.

It is also noted that definitions of the flow regimes are somewhat arbitrary. Qualitative assessment has not been done yet, and transition criteria between different flow regimes are not fully understood.

Different flow regimes are often associated with different heat transfer regimes. When phase change occurs as two-phase mixture flows along the channel, as that encountered in chilldown process, the situation is even more complicated (Carey 1992): different flow regimes are generally observed at different positions along the channel length. The sequence of flow regimes will primarily depend on the flow rate, channel orientation, fluid properties, and wall heat flux.

Some general information could be drawn from the findings of reflooding experiments designed for hypothetical loss-of-coolant accident (LOCA) in nuclear reactors, for example, the results of Chan and Banerjee (1981a, b, c) for horizontal tube and work of Cheng et al. (1978) for vertical tube. 

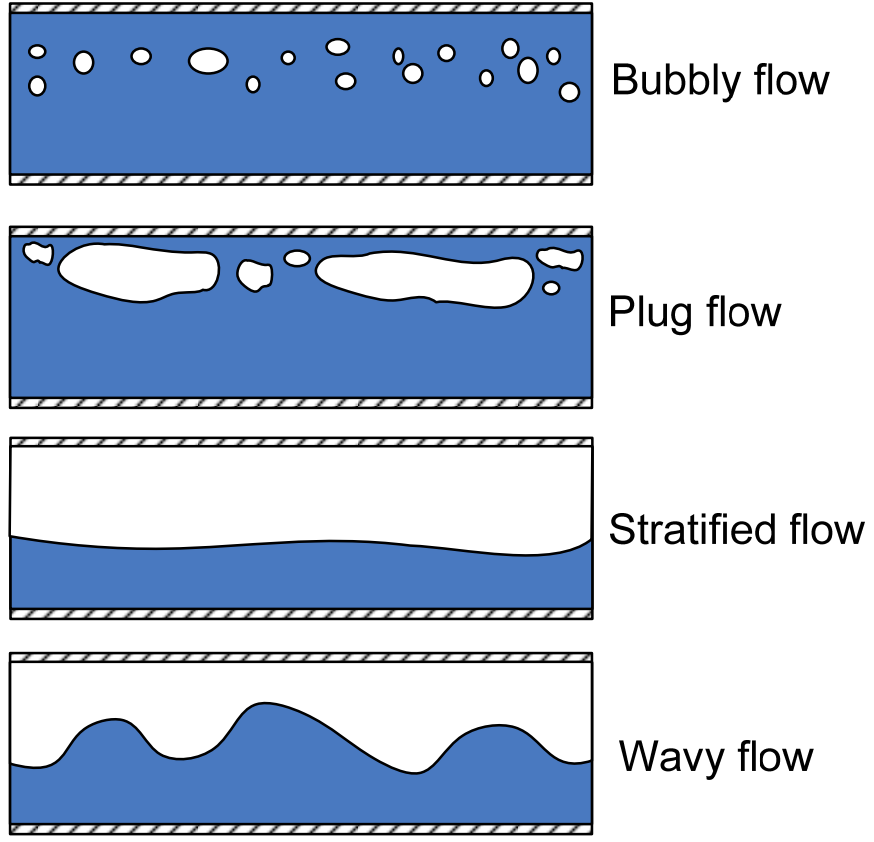

\section{Wavy flow}

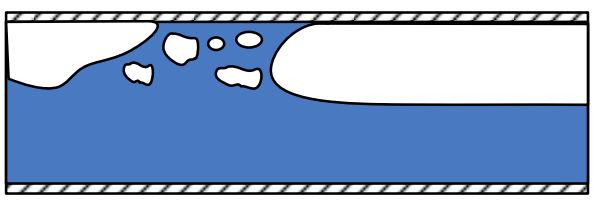

\section{Slug flow}

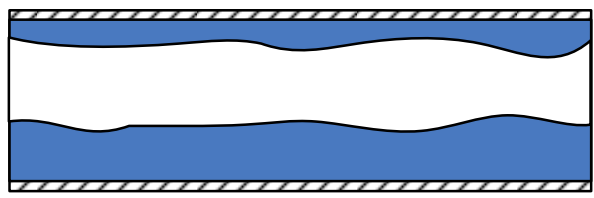

\section{Annular flow}

Fig. 2 Two-phase flow regimes inside a horizontal tube.

When the two-phase flow first enters the hot tube, the liquid phase evaporates very quickly and forms a vapor film that separates the liquid phase from touching the tube wall, and the two-phase flow is in film boiling state. Depends on the local quality and other thermo-hydraulic parameters, the flow regime can be dispersed flow or inverted annular flow. The corresponding heat transfer regime will be dispersed flow forced convection, which is also called dispersed flow film boiling (DFFB) in literature (Yadigaroglu et al. 1993; Andreani and Yadigaroglu 1996; Hammouda et al. 1997; Shah and Siddiqui 2000), or inverted annular film boiling (IAFB).

As the wall temperature decreases under certain degree, the liquid phase is able to contact the tube wall. The liquid-wall contacting front, which is often referred as quenching front (QF) or sputtering region, is characterized by violent boiling associated with significant wall temperature decrease, and propagates downstream with the flow. The heat transfer mechanism at the QF is transition boiling, which is more effective than the film boiling heat transfer. This establishment of liquidwall contact is called rewetting phenomenon and has been a research interest for several decades.

After the QF, nucleate boiling heat transfer dominates. For a vertical tube, the flow regime can be annular flow, slug flow or bubbly flow; for horizontal tube, the flow regime is generally stratified flow. With further wall temperature decrease, the nucleate boiling stage gradually changes to pure convection until the wall temperature reaches the steady state, which denotes the end of the chilldown process.

\section{Gravity Effect}

Because of the differences in density and inertia, the two phases in twophase flow are usually non-uniformly distributed across the pipe under terrestrial condition. The absence of gravity has important effects on flow regimes, pressure drop, and heat transfer of the two-phase flow. Surfacetension-induced forces and surface phenomena are likely to be much more important in space than they are on earth. Actually, all flow-regimespecific phenomena will be influenced by gravity level. As an example, Figure 3 compares the flow regime under both terrestrial and microgravity conditions; the difference is obvious.
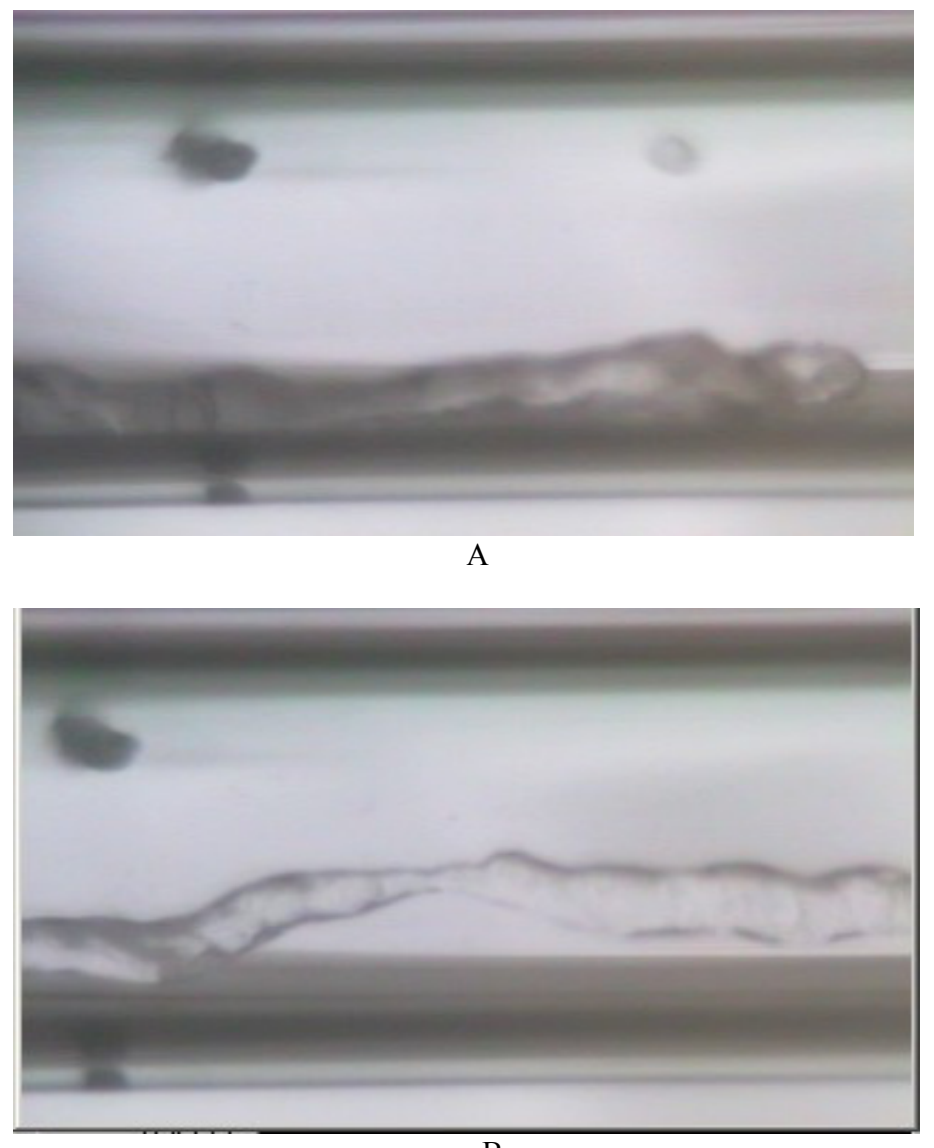

B

Fig. 3 Gravity effect on flow regimes. A) Flow regime in 1-g test. B) Flow regime in microgravity test.

Following is a simple scaling analysis that examines the gravity effects. For annular flow film boiling in a horizontal tube, the effect of gravity is assessed based on the ratio of $\mathrm{Gr} / \mathrm{Re}^{3}$, where $\mathrm{Gr}$ is the Grashof number and Re is the Reynolds number. The gravity effect is measured by the natural convection contribution characterized by the Gr, while the forced convective film boiling is scaled by the Reynolds number. According to Gebhart et al. (1988), $\mathrm{Re}^{3}$ is used in the denominator when the flow is perpendicular to gravity for a horizontal tube. $\mathrm{Re}^{2}$ is used when the flow is in the same direction of gravity. All the thermal properties are those of vapor because of film boiling. Figure 4 shows this ratio with the vapor flow velocity range of $0-0.5 \mathrm{~m} / \mathrm{s}$ and a $\Delta T$ of $100{ }^{\circ} \mathrm{C}$ for the $\mathrm{Gr}$ estimation.

Based on Figure 4, if the vapor velocity is greater than $10 \mathrm{~cm} / \mathrm{s}$, then the $\mathrm{Gr} / \mathrm{Re}^{3}$ is less than 0.2 . The natural convection is negligible for $\mathrm{Gr} / \mathrm{Re}^{3}$ less than 0.225 according to Gebhart et al. (1988). Therefore, a terrestrial gravity experiment with the vapor velocity greater than 10 $\mathrm{cm} / \mathrm{s}$ would provide results that mimic the microgravity phenomenon. 


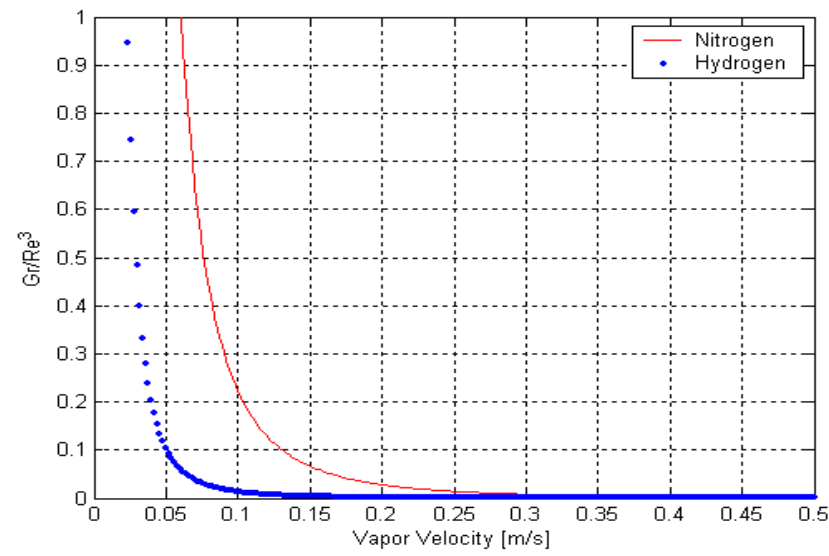

Fig. 4 Scaling analysis of gravity effects on two-phase flow.

Cryogenic two-phase flow and chilldown process is a complex problem for the scientific community to solve. The following summarizes the previous accomplishments from the experimental research.

\section{Terrestrial cryogenic boiling and two-phase flow experiments}

Numerous studies of cryogenic boiling in 1-g environment were conducted in the 1950s and 1960s. Brentari et al. (1965) gave a comprehensive review of the experimental studies and heat transfer correlations. For the fluids of oxygen, nitrogen, hydrogen and helium, it was found that for pool boiling, the Kutateladze (1952) correlation had the greatest reliability for nucleate boiling, while the Breen and Westwater (1962) correlation was best for film boiling. Maximum nucleate flux data were reasonably well predicted by the Kutateladze (1952) correlation. Although these correlations were selected as the best available, neither has particularly good agreement with experimental data. For the case of forced convection boiling, Brentari et al. (1965) reported that no correlation was found to be distinctly better. Some simple predictive methods were found to work as well as more complex schemes. In all boiling cases, it was questioned as to whether or not the predictive correlations include all of the significant variables that influence the boiling process. In particular, it was suggested that more detailed and better controlled experiments are needed and that more attention to surface and geometry effects is required.

Another comprehensive review of cryogenic boiling heat transfer addressing hydrogen, nitrogen and oxygen is given by Seader et al. (1965). It was reported that nucleate pool boiling results cannot be correlated by a single line but cover a range of temperature difference for a given heat flux. The spread is attributed to surface condition and geometry, and orientation. Maximum heat flux can be reduced by about $50 \%$ when going from $1-\mathrm{g}$ to near $0-\mathrm{g}$. Seader et al. (1965) reported a fair amount of data for film pool boiling. Film boiling heat flux is reduced considerably at near 0 -g conditions. Only a very limited amount of data is available for subcooled or saturated forced convective boiling and few conclusions were drawn. The lack of data for cryogenic forced convective boiling was also reported by Brentari and Smith (1965).

Relatively recent correlations have been published for 1-g saturated flow boiling of cryogens (Shah 1984; Gungor and Winterton 1987; Klimenko et al. 1989; Kandlikar 1990; Van Dresar et al. 2002) using the Convection number Co, Boiling number Bo and Froude number Fr as correlating parameters. Klimenko et al. (1989) investigated the effects of tube diameter and orientation on two-phase nitrogen flow and concluded that in vertical channels diameter effect was revealed in a transition from convective to less intensive nucleate boiling when the Froude number of a mixture $\mathrm{Fr}_{\mathrm{m}}$ decreases from 40 to 10 . On the contrary, in horizontal non-stratified flow, the reduction of the $\mathrm{Fr}_{\mathrm{m}}$ number was accompanied by cross-section averaged heat transfer coefficient incensement of $20-30 \%$ in the nucleate boiling region. With $\mathrm{Fr}_{\mathrm{m}} \geq 40$, the geometry and orientation did not affect the heat transfer coefficient. Van Dresar et al. (2001) experimentally studied the nearhorizontal two-phase flow of nitrogen and hydrogen. Unlike most of the other works which based on turbulent liquid flow, their work focused on laminar liquid flow and the results for low mass and heat flux flow were correlated with Froude number.

\section{$\underline{\text { Terrestrial chilldown experiments }}$}

Research on cryogenic chilldown began in the 1960s with the development of rocket launching systems. Burke et al. (1960) studied the chilldown process of stainless-steel transfer lines of 60,100 and $175 \mathrm{ft}$ long with a $2.0 \mathrm{in.}$ OD. The transfer lines were quenched by flowing liquid nitrogen. A sight glass was located near the discharge end for flow phenomena observation. Based on the wall temperature, liquid flow rate, and the observation, the chilldown process was simply divided into three stages: gas flow, two-phase flow and liquid flow. However, the flow regime information was lack in the experiments; moreover, the averaged wall temperature was used in their study. While other researchers (Bronson et al. 1962) pointed out that circumferential temperature gradient could be very large in cryogenic chilldown process. Early visualized study of flow regimes in a horizontal pipe during chilldown can be retrospect to Bronson et al. (1962). A $50 \mathrm{ft}$ long with 1.375 in. ID test section was quenched by liquid hydrogen in this work. Results showed that the stratified flow is prevalent in the cryogenic chilldown process. Based on their experiments, rudimental models (Burke et al. 1960; Bronson et al. 1962) were also suggested to calculate chilldown time. Differences in flow regimes were not considered in these models; instead a gross effect was used. The work of both Burke et al. (1960) and Bronson et al. (1962) based on extremely long transfer lines, it is doubtful that their results can be applied over a short tube.

Chi and Vetere (1964) studied the chilldown process of hydrogen flowing through a 2 -ft long thin wall copper tube. Thermocouples were installed on the outside wall and in the center of the tubing to measure the wall and stream temperatures at both the inlet and the outlet of the test section. The thermocouple beads in the center of the tubing were treated as control volume and their responses were used to identify different flow regimes. Chi and Vetere (1964) found that the void fractions were much larger, more than five times in some cases, than those given by previous investigators (Wright and Walters 1959; Hsu and Graham 1963). They attributed this difference to the effect of nonequilibrium nature of the chilldown process and concluded that thermodynamic equilibrium cannot exist in film boiling and transition regimes during chilldown. Another research work by Chi (1965) used several 26-in long aluminum tubes with 3/16 -in ID and ODs from 1/2 to

2 inch. Unlike the thin wall copper tubing experiments (Chi and Vetere 1964), the temperature responses showed that slug flow was not observed until the aluminum test sections were almost cooled down, and the dominant flow regime was mist flow.

As mentioned before, chilldown of a hot surface or tube is of fundamental importance for the re-establishment of normal and safe temperature level following dryout in a LOCA in nuclear reactors. Liquid water or common refrigerant are usually used in this type of experiments. For example, Chan and Banerjee (1981a, b, c) and later Abdul-Razzak et al. (1992) used water to chilldown a preheated horizontal tubes. In their experiments, the chilldown process was divided into three regions, namely film boiling region, partially quenched region and totally quenched region. Different heat transfer mechanisms were involved in different regions.

Kawaji et al. (1985) experimentally investigated the chilldown process inside a vertical tube with different flow rates. Their results showed that 
for high flow rate, the entering liquid will initially boil through film boiling mechanism and then develop into inverted annular flow, dispersed flow and fully vapor flow, for low flow rate, the corresponding sequence was saturated boiling, annular flow, dispersed flow and fully vapor flow.

Recently, Velat (2004) experimentally studied the cryogenic chilldown in a horizontal pipe using nitrogen as working fluid. Pyrex glass tube with vacuum jacket was used for visualization. The flow regimes were recorded by high speed camera. Wall temperature histories and pressure drop along the pipe were recorded and associated with the visualized images.

\section{$\underline{\text { Reduced gravity boiling and two-phase flow experiments }}$}

Because of the experimental difficulties there are very little heat transfer data for cryogenic flow boiling in reduced gravity. We were able to find just one report done by Antar and Collins (1997) investigated the cryogenic flow boiling in low gravity condition. The experimental results of two-phase flow under reduced gravity conditions using regular working fluids, such as R113, are also summarized here.

Adham-Khodaparast et al. (1995) investigated the flow film boiling during quenching of a hot flat surface with R-113. Micro-sensors were used to record instantaneous heat flux and heater surface temperature. They reported lower heat transfer rates during microgravity as compared to normal gravity and contributed that to thickening of the vapor layer. The wall superheat and the surface heat flux at the onset of rewetting and the maximum heat flux were found to increase with the inlet liquid subcooling, mass flux and gravity level. The effect of gravity was determined to be more important for low flow rates and less relevant for high flow rates. The two-phase flow regimes were not reported in their work.

Another quenching test under microgravity was done by Westbye et al. (1995). A hot thin-walled stainless steel tube was quenched by injection of subcooled R113 into the tube under both 1-g and microgravity conditions. The injection mass flux was $160-850 \mathrm{~kg} / \mathrm{m}^{2} \mathrm{~s}$. It was found that the rewetting temperatures were $15^{\circ} \mathrm{C}-25^{\circ} \mathrm{C}$ lower in microgravity than those obtained in 1-g, and the film boiling heat transfer coefficients in microgravity were less than those in 1-g tests. This resulted in much longer cooling periods in microgravity. It was also reported that once the tube was cooled sufficiently to allow axial propagation of the QF, the rewetting velocity was slightly greater in microgravity. The nucleate and transition boiling curves under microgravity were reported to be shifted to lower wall superheats as compared to 1-g results.

Antar and Collins (1997) reported cryogenic chilldown process under 1-g condition and on board a KC-135 aircraft. They observed that a sputtering leading core followed by a liquid filament annular flow regime. This flow regime is composed of a long and connected liquid column that is flowing in the center of the tube and is surround by a thick vapor layer. They attributed the filamentary flow to the lack of difference in the speed of vapor and liquid phases. On the heat transfer side, they reported that the quench process was delayed in low gravity and the tube wall cooling rate was diminished under microgravity conditions. The QF speed was found to be slower under the low gravity conditions.

\section{CRYOGENIC LINE CILLDOWN RESEARCH}

\subsection{Terrestrial Chilldown Experiment}

Progress of cryogenic two-phase chilldown under terrestrial condition is discussed in this section. We focus on gravity-driven flow experiments as it enhances the basic understanding of the chilldown process. The experimental system, procedure and measurement methods are provided in Yuan (2006).
In gravity-driven flow experiments, an insulated reservoir is used to generate the flow with an estimated mass flux range of $18-23 \mathrm{~kg} / \mathrm{m}^{2} \mathrm{~s}$ by reviewing the recorded flow images. The results show that the cryogenic chilldown process can be divided into three stages that are associated with different heat transfer mechanisms.

\section{Heat Transfer Study}

For the horizontal tube orientation, the two-phase flow is generally stratified because of the gravitational force. Therefore the bottom side of the tube is chilled down first. The heat transfer mechanism at the bottom of the tube includes film boiling, transition boiling, and nucleate boiling, while the heat transfer mechanism at the top of the tube is mainly due to convection by the superheated vapor.

\section{Wall temperature profiles}

Wall temperatures are measured by 16 thermocouples, 9 are embedded very close to the inner surface of the tube wall; the other 7 thermocouples measure the outside wall temperature of the test section. The thermocouple locations are shown in Figure 5. The unit for the length dimension is $\mathrm{mm}$.

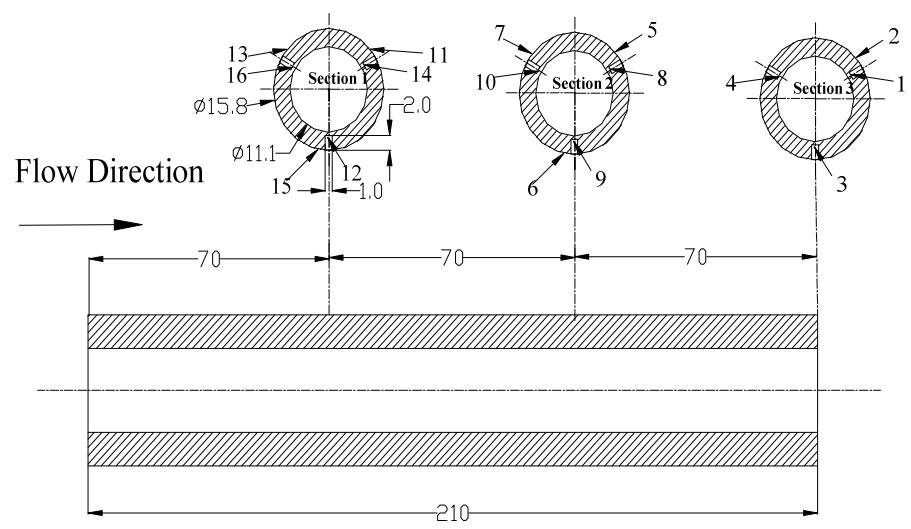

Fig. 5 Sketch of the test section and thermocouple locations for gravitydriven test.

Figure 6 gives the temperature profiles at the inlet and middle sections. It is found that a large temperature difference exists between the top and bottom of the test section, which was also reported by Bronson (1962) in the experiments of chilldown in heavy-wall transfer lines. This temperature difference suggests that different heat transfer mechanisms are encountered at the top and the bottom of the test section, respectively. Since the two phases are separated by the gravitational force, the heat transfer mechanism at the bottom is boiling heat transfer, while the heat transfer at the top is forced convection to the vapor phase.

\section{Data reduction}

In boiling heat transfer experiments, the surface heat flux as a function of the wall super heat is often of particular interest, because it denotes different heat transfer mechanisms and is crucial for engineering applications. However, in chilldown or quenching experiments, the surface heat flux can not be controlled independently. The surface heat flux can only be inferred from the wall temperature history by solving the inverse heat conduction problem (IHCP). For quenching of a vertical tube, in which the axisymmetrical assumption is generally held, the situation is much simpler. 


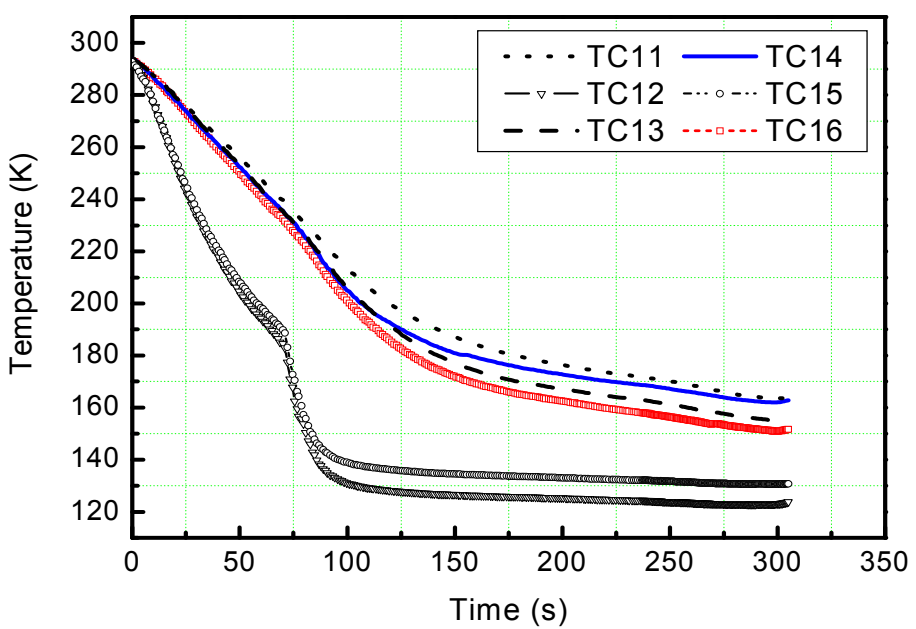

A

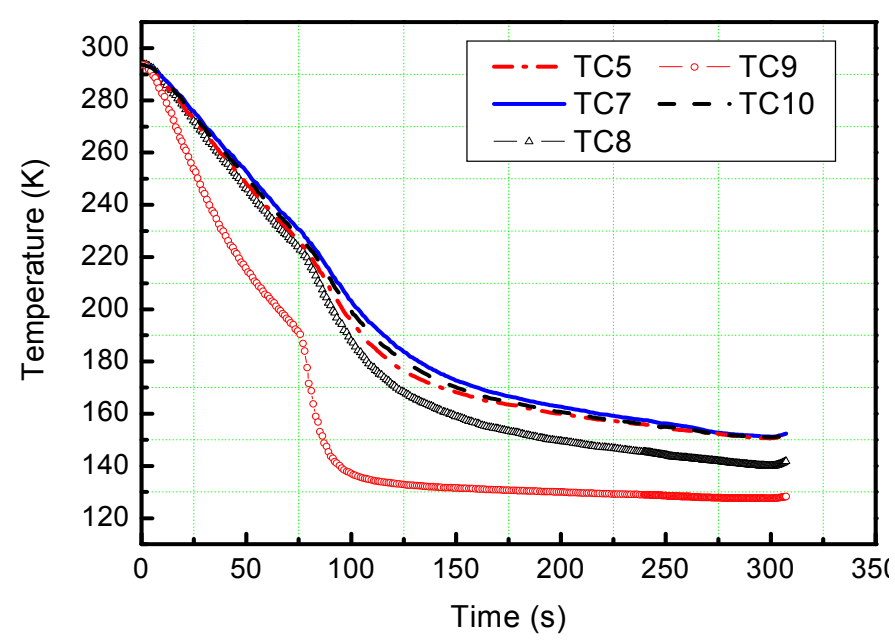

B

Fig. 6 Temperature profiles of gravity-driven test at different crosssections. A) Inlet section. B) Middle section

Based on the exact solution of the IHCP, Burggraf (1964) developed a method to obtain the temperatures and heat fluxes at the inside tube wall from the temperature history data of the thermocouple welded on the outside of the test section. The inside wall temperature is given as follows:

$$
\begin{aligned}
& T_{i}=T+\left(\frac{r_{o}^{2}}{4 \alpha}\left(\left(\frac{r}{r}\right)^{2}-1-2 \ln \frac{r i}{r_{o}}\right)\right) d T \\
& +\left(\frac{1}{64 \alpha^{2}}\left(r_{i}^{4}-5 r_{o}^{4}\right)-\frac{r_{o}^{2} r_{i}^{2}}{8 \alpha^{2}} \ln \frac{r_{i}}{r_{o}}-\frac{r_{o}^{4}}{16 \alpha^{2}} \ln \frac{r_{i}}{r_{o}}+\frac{r_{o}^{2} r_{i}^{2}}{16 \alpha^{2}}\right) \frac{d^{2} T}{d t^{2}}+\ldots
\end{aligned}
$$

where $r_{i}$ and $r_{o}$ denote the inner and outer radius, respectively; $T_{i}$ and $T$ are the inside wall temperature and temperature measured by thermocouple, respectively; $\alpha$ is the thermal diffusivity of the wall. Then the inside wall heat flux with the first three leading terms can be written as (Iloeje et al. 1975):

$$
\begin{aligned}
& q_{w}^{\prime \prime}=\rho c\left(\frac{r_{i}^{2}-r_{o}^{2}}{2 r_{i}}\right) \frac{d T}{d t}+ \\
& \left(\frac{(\rho c)^{2}}{k}\left(\frac{r_{i}^{3}}{16}-\frac{r_{o}^{4}}{16 r_{i}}-\frac{r_{o}^{2} r_{i}}{4} \ln \frac{r_{i}}{r_{o}}\right)\right) \frac{d^{2} T}{d t^{2}} \\
& +\frac{(\rho c)^{3}}{k^{2}}\left(\begin{array}{l}
\frac{r_{i}^{5}}{384}-\frac{3 r_{o}^{4} r_{i}}{128}+ \\
\left.\frac{3 r_{o}^{2} r_{i}^{3}}{128}-\frac{r_{o}^{6}}{384 r_{i}}-\frac{r_{o}^{2} r_{i}^{3}}{32} \ln \frac{r_{i}}{r_{o}}\right) \frac{d^{3} T}{d t^{3}} \\
-\frac{r_{o}^{4} r_{i}}{32} \ln \frac{r_{i}}{r_{o}}
\end{array}\right)
\end{aligned}
$$

For horizontal chilldown experiments, the axisymmetrical assumption is not valid, and the solution of the IHCP suffers from the ill-posedness. In order to calculate heat transfer data from the transient temperature profiles, an energy balance is performed locally on a control volume of the tube wall at the thermocouple location. The change in the stored heat in the control volume is equated to the heat transported to the fluid and that transferred by conduction, minus the losses to the environment. This method was used by many researchers in analyzing the data from quenching tests (Abdul-Razzak et. al 1992; Westbye et al. 1995; Chen et al. 1979). The inside wall heat flux is then given as :

$$
\begin{aligned}
& q_{w}^{\prime \prime}=-\rho c\left(\frac{r_{o}^{2}-r_{i}^{2}}{2 r_{i}}\right) \frac{d T}{d t} \\
& +\frac{k}{U^{2}}\left(\frac{r_{o}^{2}-r_{i}^{2}}{2 r_{i}}\right) \frac{d^{2} T}{d t^{2}} \\
& -\left(\frac{r_{o}}{r_{i}}\right)\left(q_{\text {conv }}^{\prime \prime}+q_{\text {rad }}^{\prime \prime}\right)+\frac{\left(r_{o}-r_{i}\right)}{r_{o} d \varphi} q_{c o n d}^{\prime \prime}
\end{aligned}
$$

In the above, $U$ is the rewetting velocity. The first term in the righthand-side (RHS) of Equation (3) comes from the change of the stored heat in the control volume and is the dominant term in chilldown experiments. It is also interesting to note that this term equals the first term from the IHCP solution given in Equation (2).

To estimate the axial heat conduction term in rewetting experiments, Chen et al. (1979) assumed a constant rewetting velocity U, and the axial temperature gradient $(d T / d z)$ was represented by $(1 / U)(d T / d z)$. Then the effect of the axial conduction on the inside wall heat flux can be evaluated from the second term in the RHS of Equation (3). The axial conduction term is generally very small, and it is only important at the location near the quenching front, where the maximum axial temperature gradient exists between the dry side and the wet side of the wall. A comparison between the heat fluxes based on a 2-D heat transfer model (Cheng 1978), which considers the axial heat conduction, with those obtained by neglecting the axial conduction was given by Cheng et al. (1979). The comparison for the copper test section showed that the two mid-plane boiling curves were approximately the same and the net axial conduction at the mid-section is negligibly small. In our experiments, the temperature measurements show that the axial temperature gradient is relatively small, and additionally the heat conductivity of the glass is much smaller than that of the copper used by Cheng et al.(1979), therefore the axial heat conduction along the test section is neglected in the heat flux calculation. It is left in Equation (3) only for completeness.

The third term in Equation (3) accounts for the contribution from the radiation and natural convection inside the vacuum jacket. The last term 
in Equation (3) comes from the circumferential heat transfer. Here, $d \varphi$ is the differential azimuthal angle of the control volume and depends on the size of the control volume. In our calculation, the control volume is approximately assumed to be in thermal equilibrium with the embedded thermocouple. Based on this assumption, the control volume size is chosen with an average arc length of $2.0 \mathrm{~mm}$. The circumferential temperature gradient is calculated by a linear interpolation between the thermocouple measuring points.

Derivative of the temperature history is needed in calculating the first term in Equation (3). Generally, the finite difference method is not suitable to obtain the temperature derivatives, because it is very susceptive to small fluctuations, which are inevitable in measurements. Therefore, a least square technique, proposed by Iloeje et al. (1975) in a similar situation, is used to get smooth profiles. To increase accuracy, the temperature data are divided into segments and the order of the curve fit used for each segment is made as high as possible (but less than 6 , otherwise it will be subject to temperature fluctuations) without reintroducing irregularities inherent in the raw data. Figure 7 shows a typical result obtained with the least square fit procedure, and Figure 8 compares the first term in Equation (3) calculated from the least square fit line with that from the finite difference method. It is clear that the finite difference method is not suitable for calculating the derivatives of measured temperature profiles.

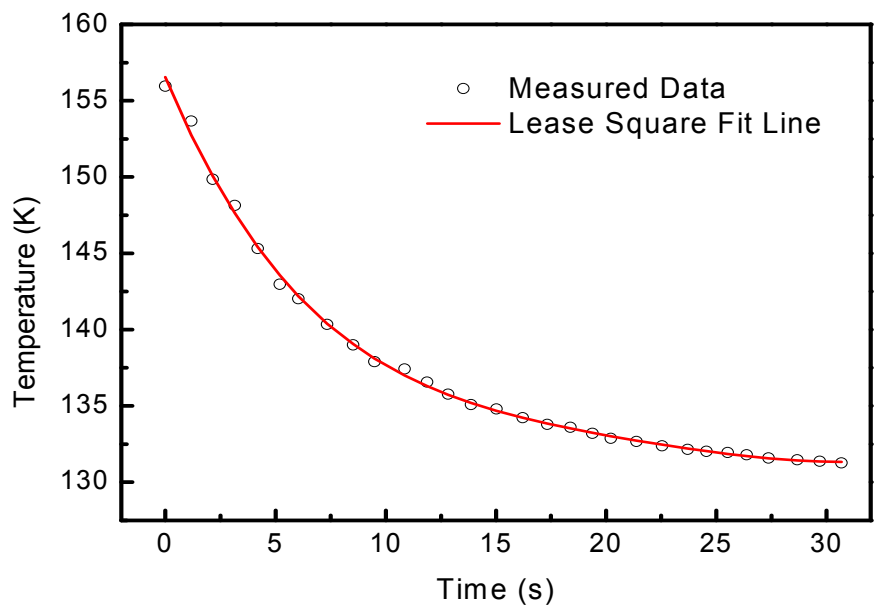

Fig. 7 Typical curve fit line of the experimental data.

We assume the vacuum jacket and the test section as long concentric cylinders, the radiation contribution to the heat flux, $q_{\text {rad }}^{\prime \prime}$, is then obtained by (Incropera and Dewitt 2002; Liao 2005):

$$
q_{\text {rad }}^{\prime \prime}=\frac{\sigma_{B}\left(T_{j}^{4}-T_{o}^{4}\right)}{\frac{1}{\varepsilon_{t}}+\frac{1-\varepsilon_{j}}{\varepsilon_{j}}\left(\frac{r_{o}}{r_{j}}\right)}
$$

where $\sigma_{B}$ is Stefen-Boltzmann constant, $T_{j}$ is the temperature of the vacuum jacket, and is assumed to equal the room temperature, $T_{o}$ is the outer wall temperature of the test section, $\varepsilon_{j}$ and $\varepsilon_{t}$ are the emissivity of the vacuum jacket and the test section, respectively, and $r_{o}$ and $r_{j}$ are the outer radius of the test section and the inner radius of the vacuum jacket, respectively.
To evaluate the natural convection heat transfer due to the residual air inside the vacuum jacket, Raithby and Hollands' correlation (Raithby and Hollands 1975; Liao 2005) is used:

$$
q_{c o n v}^{\prime \prime}=\frac{k_{e f f}}{r_{o} \ln \left(r_{j} / r_{o}\right)}\left(T_{j}-T_{o}\right)
$$

where $k_{\text {eff }}$ is the effective thermal conductivity given by Raithby and Hollands (1975).

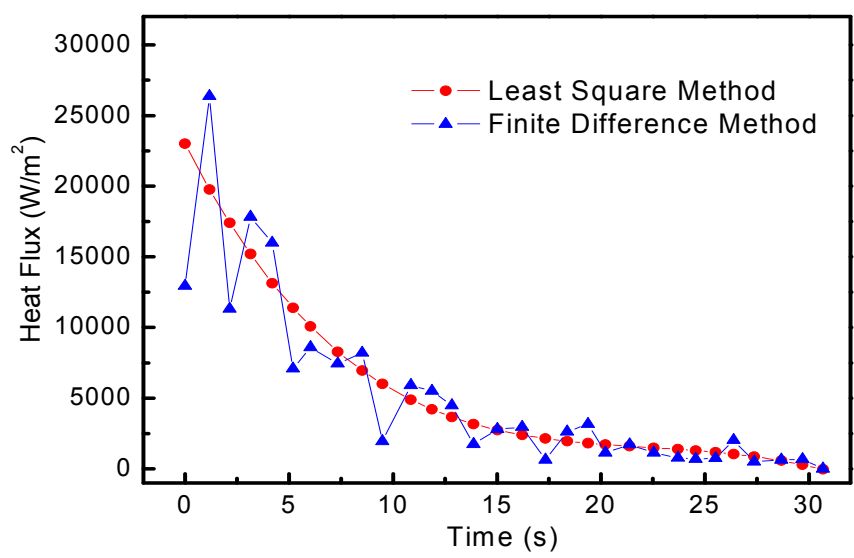

Fig. 8 Temperature derivatives calculated by least square fit method and by finite difference method

\section{$\underline{\text { Heat transfer mechanisms }}$}

The data reduction method given above is used to analyze the transient temperature measurements. Left part of Figure 9 shows the calculated bottom wall heat flux as a function of the bottom wall temperature at the outlet location, while the right part represents the corresponding temperature profiles.

The shape of bottom heat flux is similar to the boiling curve from steady-state pool boiling experiments. This suggests that the chilldown process may share many common features with pool boiling experiments. Following the method to characterize different heat transfer mechanisms in pool boiling experiments, a maximum or critical heat flux (CHF) $q_{C H F}^{\prime \prime}$ and a minimum heat flux $q_{\min }^{\prime \prime}$ are used to divide the chilldown heat transfer into three stages, which are film boiling, transition boiling and nucleate boiling, as shown in Figure 9.

Initially, the wall temperature is very high, liquid nitrogen evaporates voraciously when enters the test section; a vapor film will form and separate the liquid from contacting the wall, the two-phase flow is therefore in the film boiling stage. At decreased wall temperatures, the liquid begins to contact the wall and the heat transfer mechanism is transition boiling, which is characterized by increasing wall heat flux with decreasing wall superheat that is contrary to what in the film boiling region and nucleate boiling region. After passing the $\mathrm{CHF}$ point the heat transfer mechanism then changes to nucleate boiling.

The calculated bottom wall heat flux as a function of time is shown in Figure 10. It is obvious that the time of transition boiling is very short compared with the other two boiling stages. 


\section{Wall Temperature $(K)$}
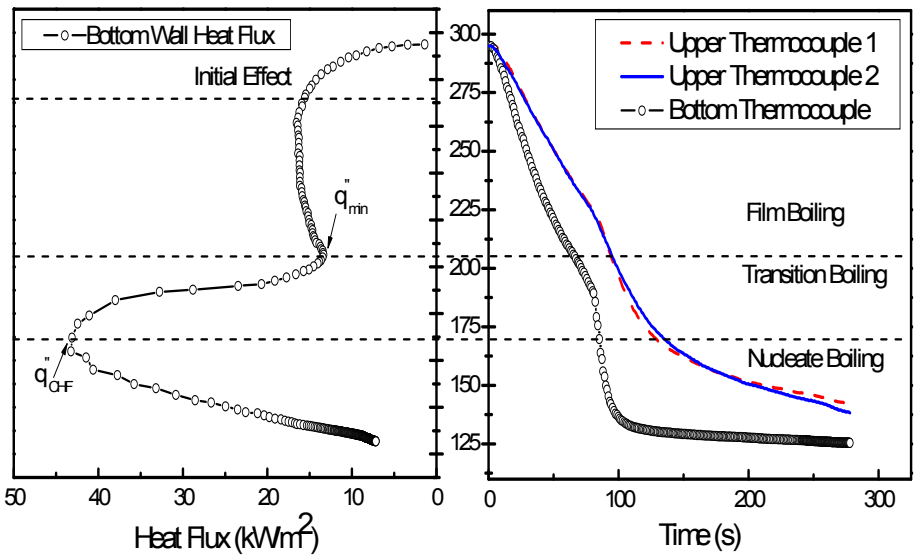

Fig. 9 Bottom wall heat flux and transient wall temperature profiles at the outlet cross-section.

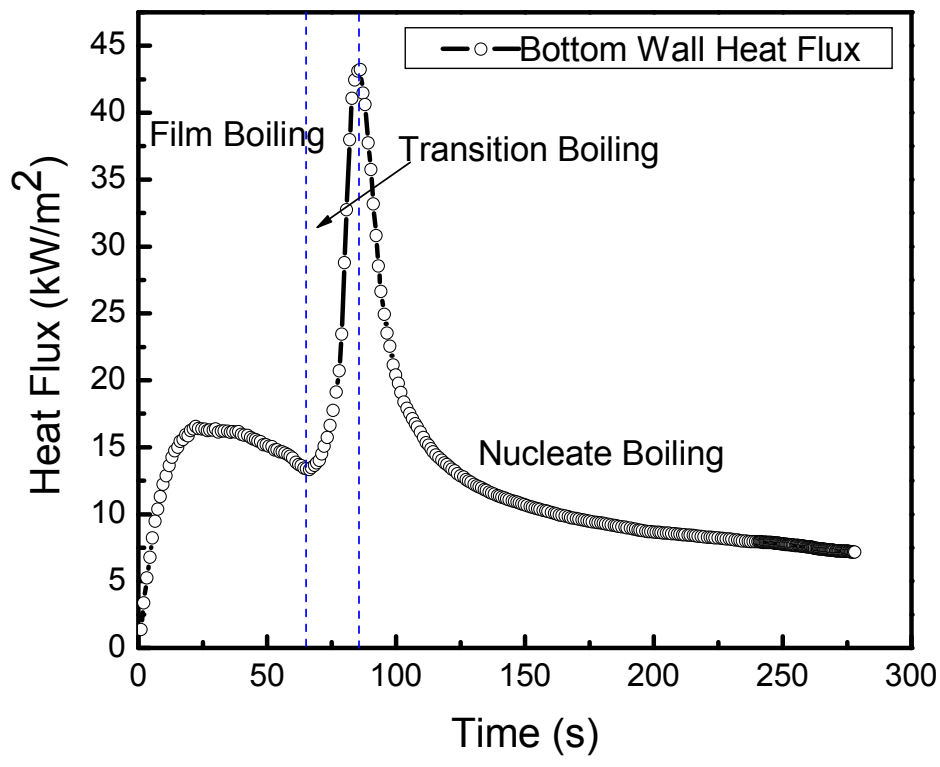

Fig. 10 Bottom wall heat flux at the outlet cross section as a function of time.

Similarity between the chilldown boiling curve and the pool boiling curve naturally leads one to compare the chilldown data with pool boiling correlations. The comparisons between the two turning points, namely the minimum heat flux and the CHF, are given below.

For the steady state film boiling, the correlation developed by Zuber (1959) is widely used to predict the minimum heat flux:

$q_{\text {min }}^{\prime \prime}=C h_{l v} \rho_{v}\left[\frac{\sigma g\left(\rho_{l}-\rho_{v}\right)}{\left(\rho_{l}-\rho_{v}\right)^{2}}\right]^{1 / 4}$

here, $\sigma$ is surface tension; $g$ is gravitational acceleration; $h_{l v}$ is the latent heat of vaporization, while $C$ was suggested differently as 0.177 (Zuber 1959), 0.13 (Zuber 1958), or 0.09 (Berenson 1961). The resulting $q_{\min }^{\prime \prime}$ is then $13.0 \mathrm{~kW} / \mathrm{m}^{2}, 9.6 \mathrm{~kW} / \mathrm{m}^{2}$, and $6.6 \mathrm{~kW} / \mathrm{m}^{2}$, respectively. In
Figure 9, the $q_{\min }^{\prime \prime}$ for chilldown is calculated as $13.3 \mathrm{~kW} / \mathrm{m}^{2}$, which is a slightly larger than the steady state prediction with $C=0.177$.

Based on the similarity between the CHF condition and column flooding, Kutateladze (1948) derived the following relation for the pool boiling CHF:

$$
q_{C H F}^{\prime \prime}=0.131 h_{l v} \rho_{v}\left[\frac{\sigma g\left(\rho_{l}-\rho_{v}\right)}{\rho_{v}^{2}}\right]^{1 / 4}
$$

Zuber (1959) proposwed the identical correlation based on the analysis of Taylor and Helmholtz instability. For liquid nitrogen under atmospheric pressure, Equation (7) gives a CHF value of $160.7 \mathrm{~kW} / \mathrm{m}^{2}$ . The chilldown measurement in Figure 10 is only about $27 \%$ of this value. This big discrepancy is believed to come from the different experimental conditions between the chilldown and the pool boiling tests. In pool boiling experiments, the heat supplied to the fluid is maintained by a heater, while in chilldown tests it comes from the stored heat in the tube wall. In the film boiling region, the heat flux is generally small, therefore the tube wall can maintain a near constant heat flux condition and functions like the heater used in the pool boiling tests. However, in the transition boiling region, the stored energy in the tube wall is depleted so quickly that the experimental condition is very different from that of the pool boiling tests. The limited energy stored in the tube wall put a restriction on the value of $\mathrm{CHF}$, which, therefore, is much less than that in the pool boiling data. Previous work by Bergles and Thompson (1970) also concluded that quantitively the differences between chilldown and steady-state boiling curves can be very large.

In Equation (6) and Equation (7), the minimum heat flux and CHF are not correlated with the thermal properties of the wall for pool boiling tests. However, as seen from above, the available heat flux to the flow is closely related to the energy stored in the wall. Therefore, the thermal properties, e.g. thermal conductivity, heat capacity, of the wall are expected to play a role in the chilldown process. For example, for the wall with a higher thermal conductivity, the energy transferred to the flow can be more quickly supplied by the surroundings, and therefore this will result in a higher value of CHF.

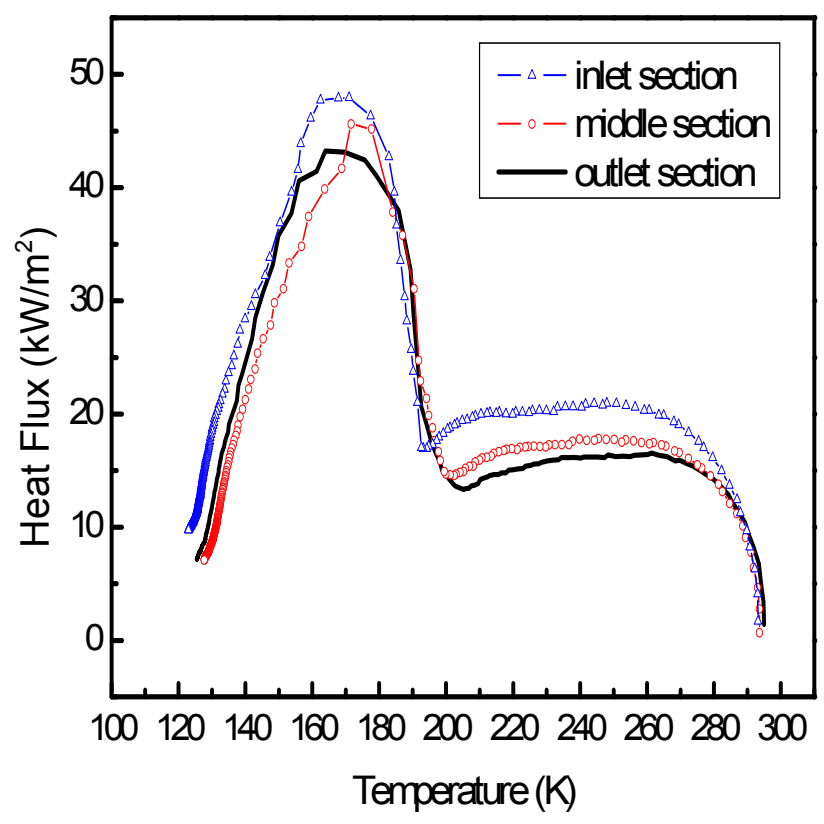

Fig. 11 Bottom wall heat fluxes at different axial locations. 
Figure 11 shows the calculated heat flux in different axial locations. It is found that both the CHF and the minimum heat flux decrease with increasing axial distance from the inlet. This is also associated with an increase in the rewetting temperature.

In most of the previous quenching experiments, the film boiling heat flux was reported as either keeping a relatively constant value (Westbye et al. 1995; Cheng and Ragheb 1979) or decreasing as the test section is chilled down (Ganić and Rohsenow 1977; Bergles and Thompson 1970). In our experiments, however, the local heat flux first increases in a short period and then decreases gradually. This is consistent with the transient nature of the experiments. Generally the increasing period is expected to be shorter at higher mass fluxes if the other conditions are kept the same. The mass fluxes in previous investigations were much larger than that in current experiments, and therefore associated with a very short increasing time of the heat flux in the film boiling regime. This might be the reason that the increases of the heat flux were not recorded before.

\section{Visualization Study}

Heat transfer analysis shows the chilldown process can be divided into three stages with each stage associated with different heat transfer mechanisms. The visualization study casts more light on the characteristic of flow regimes during the chilldown process.

Figure 12 illustrates the overall chilldown sequence in our experiments, while some selected flow images in different region of chilldown are shown in Figure 13. In the beginning of the film boiling region, the flow pattern is basically dispersed flow, in which the liquid phase is dispersed as near spherical drops within a continuous vapor phase. The void fraction of the two-phase flow decreases as the tube is chilled down, and long liquid filaments, separated from wall by a thin vapor film, are observed to flow along the tube bottom. The length of the liquid filaments generally increases with decreasing wall temperature. For short liquid filaments, the flow regime is close to dispersed flow, while for very long filaments, the flow regime can be classified as highly skewed inverted annular flow. In the film boiling region, heat is primarily transferred from the wall by conduction through the vapor film and thus evaporate the liquid filaments, and by convection to the vapor phase.

Once the bottom wall temperature has been reduced low enough, transient boiling, characterized by intermittent liquid-wall contact and violent bubble generation, is observed. Shortly after the transient boiling, a continuous liquid-wall contact is established and the liquid nitrogen begins to pile up on the bottom wall. Many nucleation sites are observed to be suppressed as the wall temperature keeps decreasing. The prevailing boiling regime is nucleate boiling and the flow pattern is stratified flow or wavy flow.

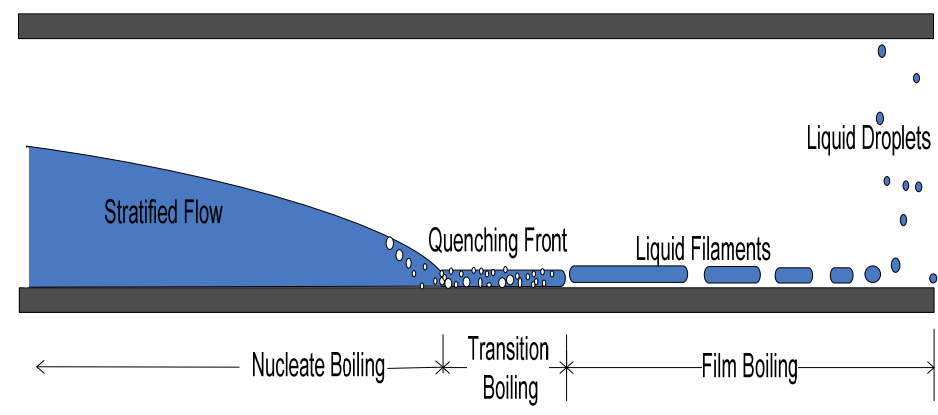

Fig. 12 Characteristics of horizontal chilldown under low flow rate.

Previous horizontal quenching tests (Chan and Banerjee1981a; AbdulRazzak et al. 1992) showed the same sequence as our experiments, however, with different flow regimes mainly in the film boiling region. In their experiments, the flow regime in film boiling was inverted annular flow. The thickness of the liquid core increases with decreasing wall temperature, and then follows the stratified flow regime. While in our experiments, the thickness of the liquid filament is generally a constant, instead the liquid thickness increases in the nucleate boiling region as shown in Figure 12.

The difference in flow regimes is believed mainly due to different flow rates. The flow rate in the test of Chan and Banerjee (1981a) was about $150 \sim 450 \mathrm{~kg} / \mathrm{m}^{2} \mathrm{~s}$, while it was even higher $\left(400 \sim 1300 \mathrm{~kg} / \mathrm{m}^{2} \mathrm{~s}\right)$ in the experiments by Abdul-Razzak et al. (1992). In current chilldown test, the flow rate is much lower. The heat stored in the tube wall causes dry-out of the liquid phase in the film boiling region and thus leads to the dispersed flow.

The visualization study also gives the detail of propagation the quenching front and how the liquid rewets the tube wall (Figure 14). The arrow in Figure 14 indicates the limit between the quenching front and the nucleate boiling region.

As shown in Figure 14, the quenching front is characterized by vehement bubble generation and intermittent liquid-wall contact. Following the quenching front, a continuous liquid-wall contact is established, the flow regime changes to stratified flow, and many nucleation sites are suppressed.

\subsection{Cryogenic Line Chilldown under Microgravity Condition}

Efficient and safe utilization of cryogenic fluids in a spacecraft during space missions demands thorough study of cryogenic two-phase flow and heat transfer under microgravity condition. However, researches on this field are very limited due to the experimental difficulties. In present study, experimental study of cryogenic chilldown under microgravity condition is conducted. The investigation focuses on the film boiling region. The microgravity experiments were performed in the 1.8 -second drop tower at the University of Florida. The experimental system, procedure and measurement methods are provided in Yuan (2006).

\section{Film Boiling under Microgravity}

Among the various film boiling correlations for pool boiling, it is very interesting to note that the surface heat flux or heat transfer coefficient is usually correlated with $g^{1 / 4}$, in which $g$ is the gravitational acceleration. For example, the highly cited Bromley's correlation (Bromley 1950) for horizontal tubes is:

$$
h_{f b}=0.62\left[\frac{k_{v}^{3} h_{l v}^{\prime} \rho_{v} g\left(\rho_{l}-\rho_{v}\right)}{\mu_{v} D \Delta T_{w}}\right]^{1 / 4}
$$
1961)

For a horizontal surface, the mostly used correlation gives (Berenson

$$
h_{f b}=0.425\left[\left(\frac{k_{v}^{3} h_{v}^{\prime} \rho_{v} g\left(\rho_{l}-\rho_{v}\right)}{\mu_{v} \Delta T_{w}}\right)\left(\frac{g\left(\rho_{l}-\rho_{v}\right)}{\sigma}\right)^{1 / 2}\right]^{1 / 4}
$$

in which the $\left(g\left(\rho_{l}-\rho_{v}\right) / \sigma\right)^{1 / 2}$ term is actually a geometrical factor as pointed out by Berenson (1961), and has the dimension of $\left[\mathrm{m}^{-1}\right]$, thus in Equation (9) the film boiling heat transfer coefficient is still proportional to $g^{1 / 4}$. Liao (2005) and Chan (1995) also report the same relation. The list also includes the correlations given by Noyes (1963), Chang and Snyder (1960), etc. The only exception, to our knowledge, is the correlation proposed by Chang (1959), in which the film boiling heat transfer coefficient is suggested to be proportional to $g^{1 / 3}$.

It is also noted that some of the above correlations were derived based on quite different approaches, such as the analytical solution of flow in vapor film channel (Chan 1995; Liao 2005) and the vapor escape model based on Taylor-Helmholtz instability (Berenson 1961). 

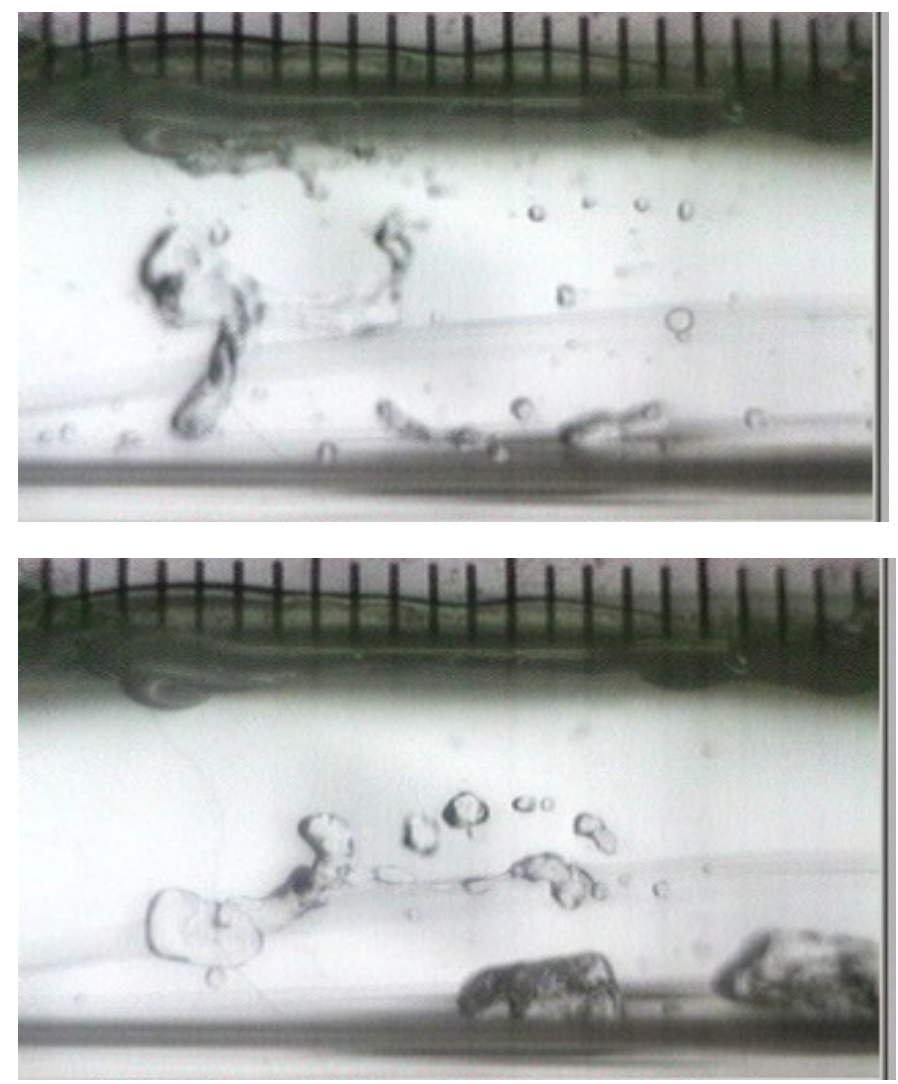

A
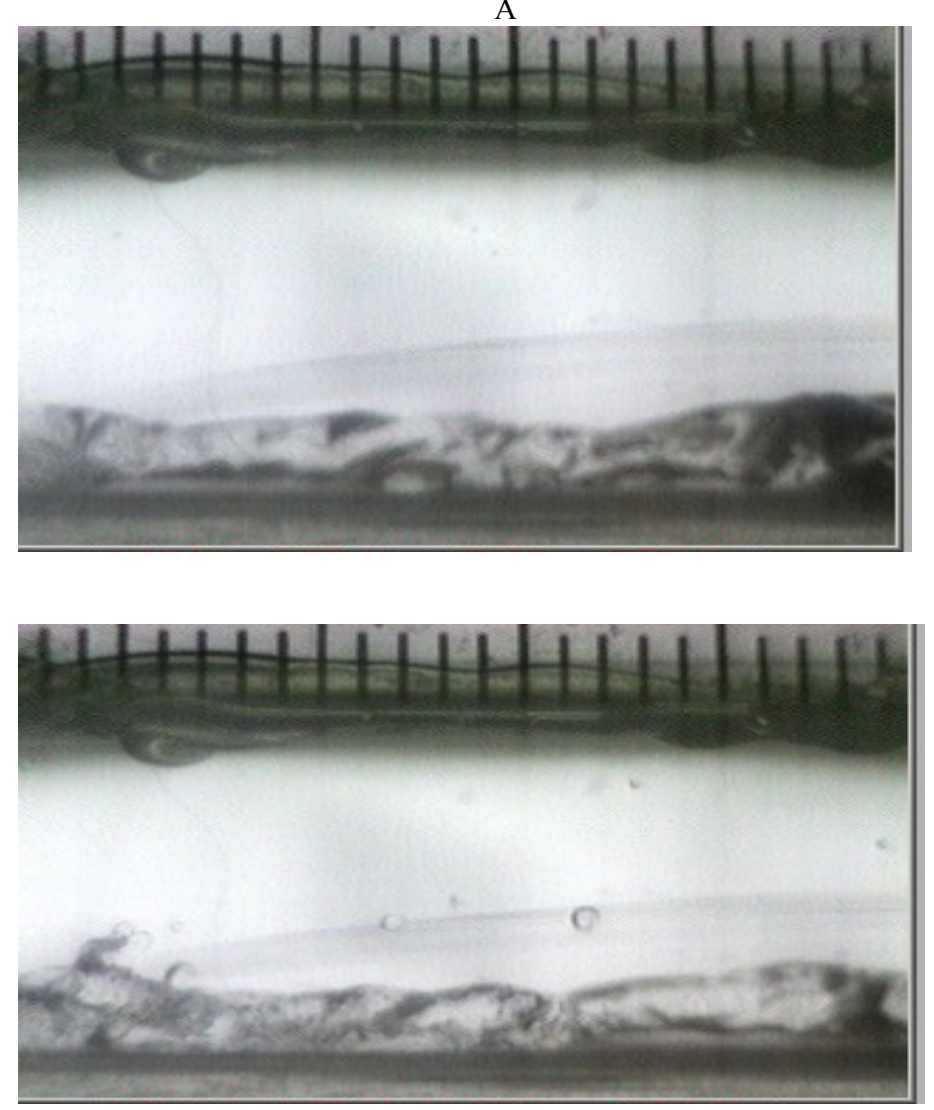

B
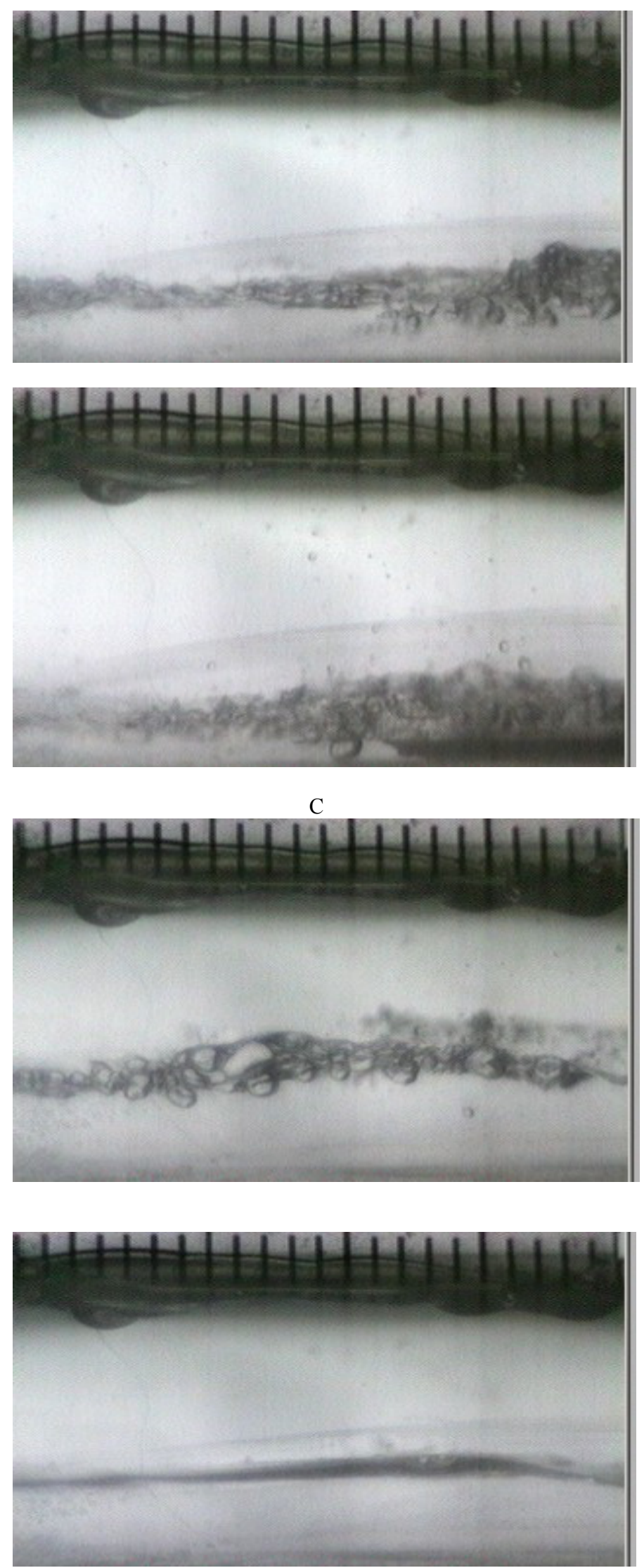

D

Fig. 13 Flow visualizations at different stages of chilldown. A) Initial stage. B) Film boiling stage. C) Transition boiling stage. D) Nucleate boiling stage. 

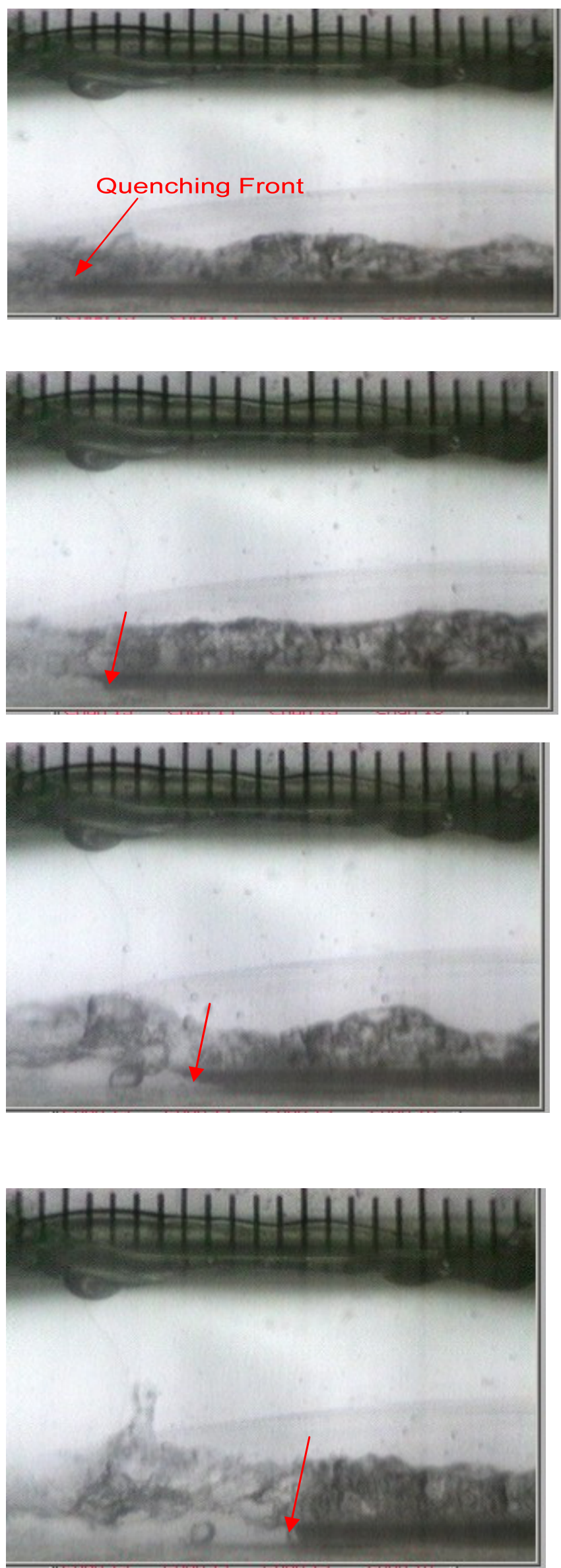

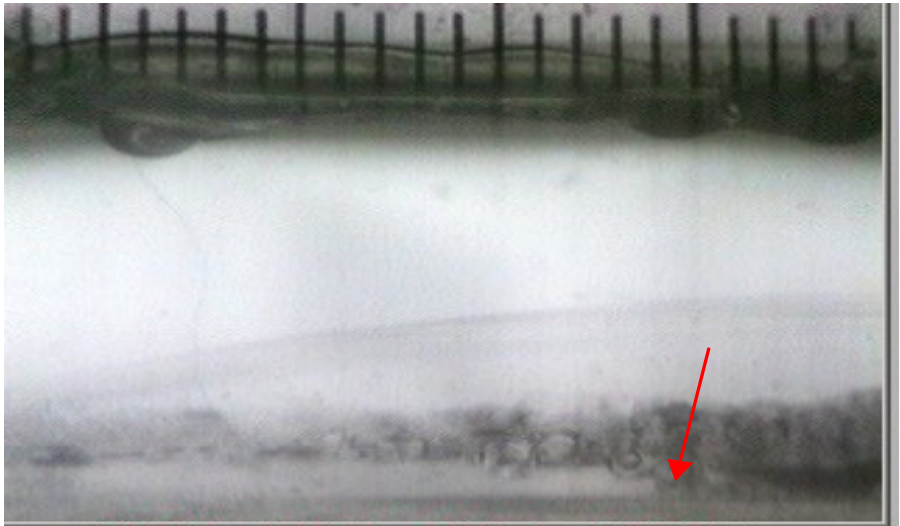

Fig. 14 Propagation of the quenching front.

Therefore, it is natural for one to think that the heat transfer characteristics in film boiling are related to $\mathrm{g}^{1 / 4}$ and we can extend the above correlations to different g-levels. For example, the Bromley's correlation can be modified as:

$h_{f b}=0.62\left[\frac{k_{v}^{3} h_{l v}^{\prime} \rho_{v} g\left(\rho_{l}-\rho_{v}\right)}{\mu_{v} D \Delta T_{w}}\left(\frac{a}{g}\right)\right]^{1 / 4}$

in which, $a$ is the specific local acceleration.

Table 1 Basic findings of flow film boiling in previous chilldown experiments.

\begin{tabular}{||l|l|l|l||}
\hline \hline & $\begin{array}{l}\text { Adham- } \\
\text { Khodapar } \\
\text { ast et al. } \\
(1995)\end{array}$ & $\begin{array}{l}\text { Westbye et al. } \\
(1995)\end{array}$ & $\begin{array}{l}\text { Antar and } \\
\text { Collins (1997) }\end{array}$ \\
\hline $\begin{array}{l}\text { Experimental } \\
\text { apparatus }\end{array}$ & $\begin{array}{l}\text { horizontal } \\
\text { surface }\end{array}$ & $\begin{array}{l}\text { horizontal } \\
\text { tube }\end{array}$ & vertical tube \\
\hline Working fluid & R113 & R113 & LN $_{2}$ \\
\hline $\begin{array}{l}\text { Flow pattern } \\
\text { NA transfer }\end{array}$ & lower & $\begin{array}{l}\text { inverted } \\
\text { annular flow }\end{array}$ & $\begin{array}{l}\text { liquid filament } \\
\text { annular flow }\end{array}$ \\
\hline $\begin{array}{l}\text { Heat } \\
\text { rate } \\
\text { microgravity }\end{array}$ & lower & lower & lower \\
\hline $\begin{array}{l}\text { Rewetting } \\
\text { temperature } \\
\text { under } \\
\text { microgravity }\end{array}$ & NA & higher & lower \\
\hline $\begin{array}{l}\text { Rewetting } \\
\text { speed under } \\
\text { microgravity }\end{array}$ & & & \\
\hline \hline
\end{tabular}

However, experiments by Merte and Clark (1964) showed that the heat flux and the Nusselt number were proportional to $(a / g)^{1 / 3}$ in the gravity range of $0.01<a / g<1$. On the other hand, the maximum and minimum heat fluxes were found to depend on gravity according to $(a / g)^{1 / 4}$. Unlike most of the other microgravity pool boiling research, which were performed under steady or quasi-steady conditions with a constant wall heat flux or a constant wall temperature, the experiments by Merte and Clark (1964) were highly transient. In their experiments, a 
small ball was quenched inside the saturated liquid nitrogen under different g-levels, the temperature of the ball kept decreasing, to this extent, their experimental condition was close to a cryogenic chilldown process. The drop tower used in their experiments can provide a free fall time of about 1.4 seconds.

For flow boiling experiments, the flow will play a role in both bulk convection and vapor removal mechanism, therefore the heat transfer coefficient will not have a simple relation with the local acceleration as that in pool boiling.

Chilldown investigations in reduced gravity is very limited, all of the previous experiments found in the open literature have been reviewed above. The basic findings for the flow film boiling are summarized in Table 1. All previous research reported lower heat transfer rates in reduced gravity, Adham-Khodaparast et al. (1995) attributed this reduction to the thickening of the vapor film.

\section{Experimental Condition}

Since the microgravity duration is relatively short, the experiment is designed to drop the apparatus at different wall temperatures with different mass fluxes. The wall temperatures are classified as three groups that are high wall temperature (about 270K), medium wall temperature (about 240K) and low wall temperature (about 210K). Different motor speeds are used to generate different mass fluxes.

The gravity level and the deceleration impact have been measured by an accelerometer (Omega ACC104A) mounted on an aluminum piece that is attached to the drag shield.

\section{Flow Regime Visualization under Microgravity Condition}

The flow regimes before and during the drop are compared in Figure 15 and Figure 16. The images on the left are taken before drop, while the microgravity images are on the right. With the experimental wall temperature range, the two-phase flow is in the dispersed flow film boiling (DFFB) state and the liquid phase is either in the form of small droplets or long filaments before drop. The characteristics of the 1-g flow regime are summarized in previous section.

Different flow behaviors have been recorded during the microgravity period. If the liquid phase before drop is in the form of dispersed droplets, these droplets will enter the central region still as droplets during the microgravity period (Figure 15B). For long liquid filaments, sometimes the filaments are lifted up and still maintain original shape during the drop (Figure 15D); in some other cases, the liquid filaments are broken and dispersed into the central region (Figure 16F) or the two-phase flow has a liquid-vapor core in the center with smaller liquid chunks at both top and bottom (Figure 16H).

Heat Transfer Study

Due to the thickening of the vapor film, the heat transfer rate in film boiling is generally lower under microgravity condition. However, this effect is expected to be relatively less important with increasing flow speeds. In this section, the heat transfer in the film boiling region under microgravity is discussed.

\section{Wall Temperature Profiles}

To get more data points during the microgravity period, the wall temperatures are measured only at one axial location. Figure 17 gives the typical temperature profiles with different mass fluxes.

The circled temperatures in Figure 17 approximately indicate the drop period, which includes release of the drag shield, microgravity period, impact on the air bag, and deceleration period.

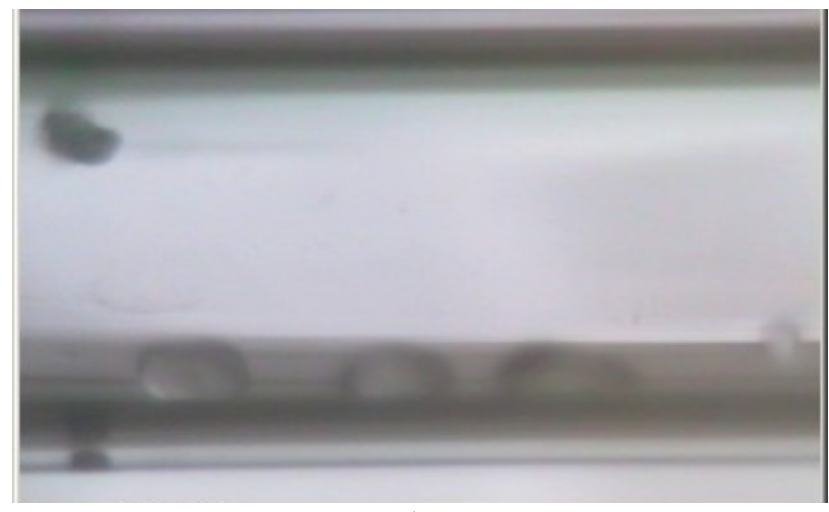

A

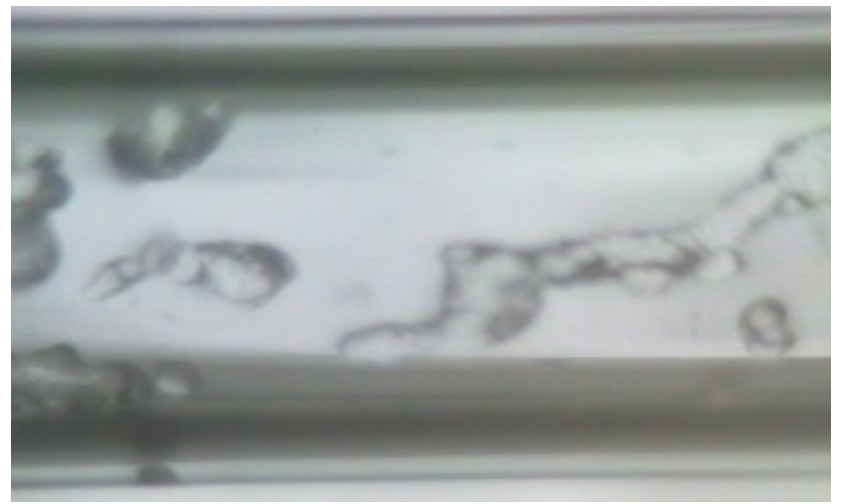

B

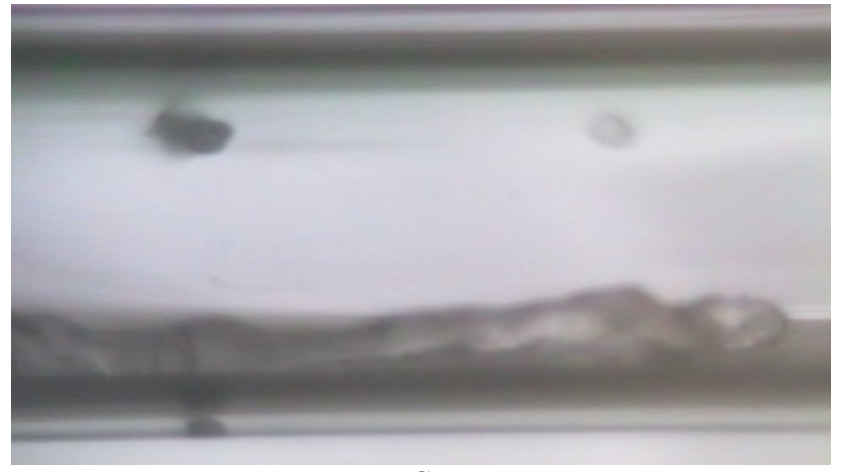

$\mathrm{C}$

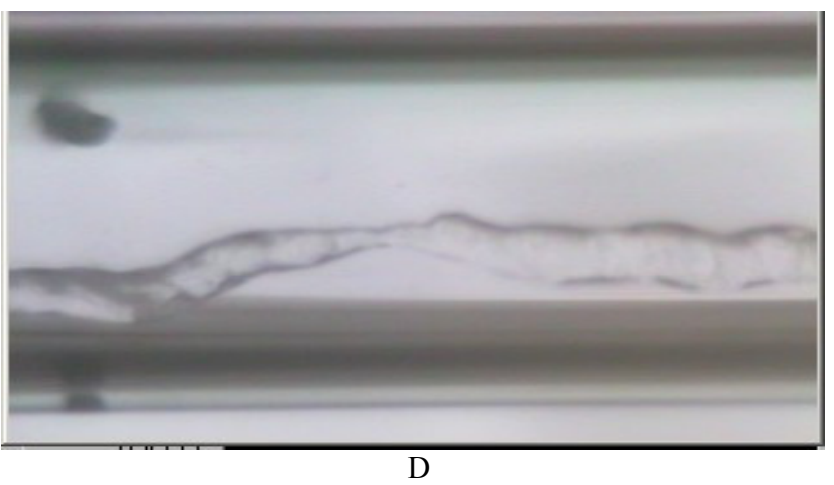

Fig. 15 Two-phase flow images under both 1-g and microgravity conditions. A) 1-g case 1 . B) Microgravity case 1 . C) 1 -g case 2. D) Microgravity case 2 . 


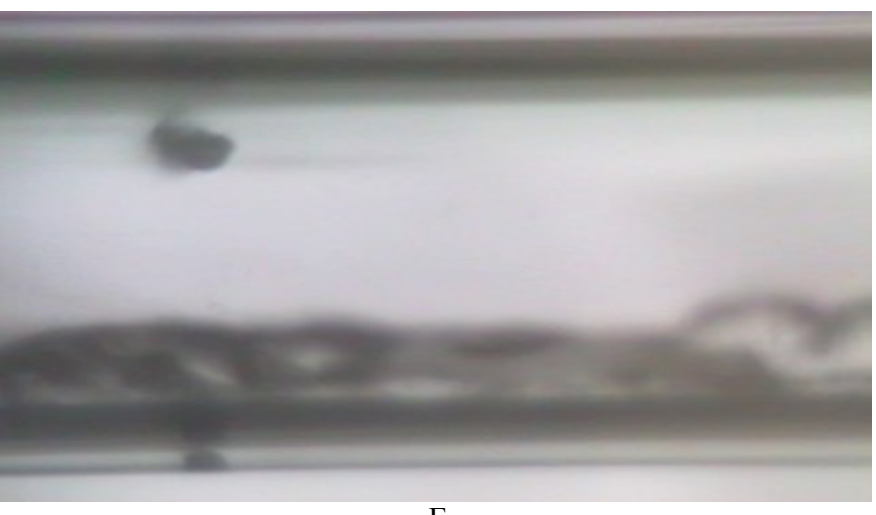

$\mathrm{E}$

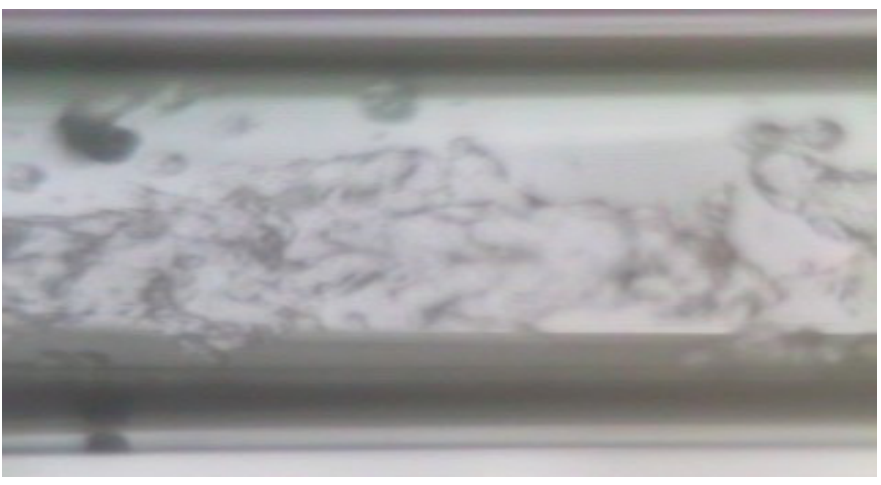

$\mathrm{F}$

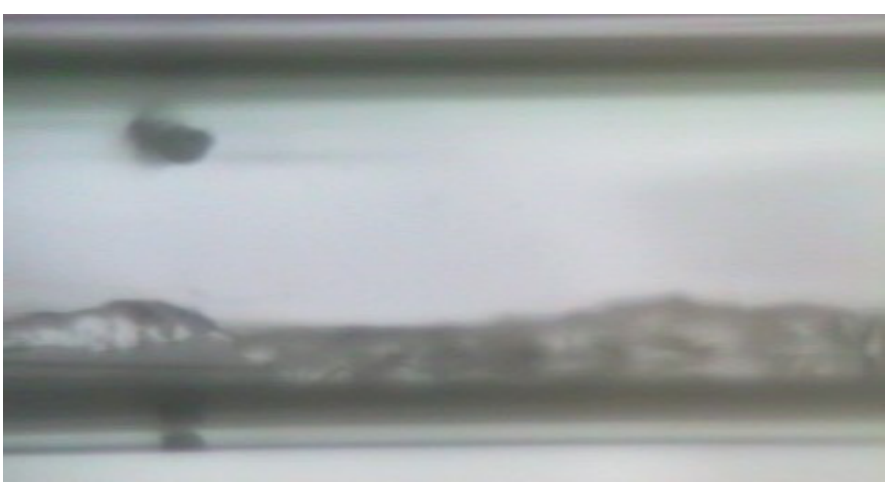

G

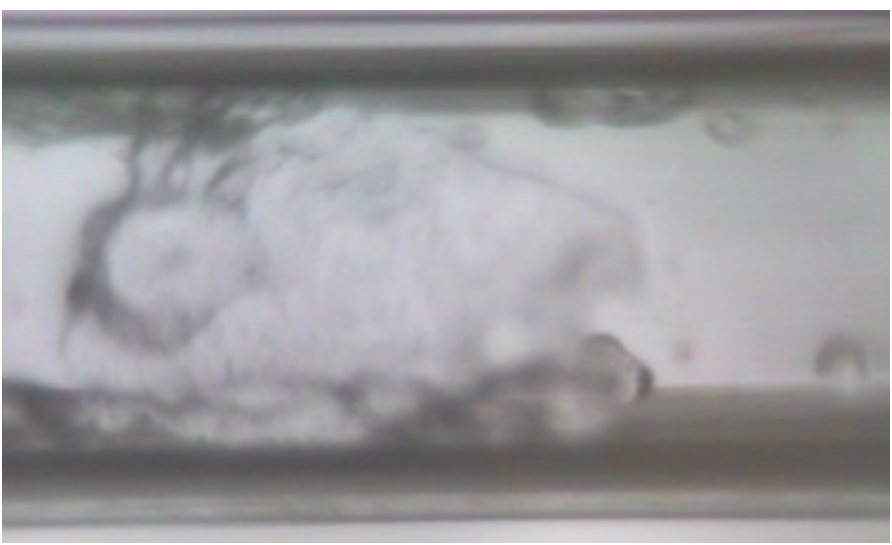

$\mathrm{H}$

Fig. 16 Two-phase flow images under both 1-g and microgravity Conditions E) 1-g case 3. F) Microgravity case 3. G) 1-g case 4. H) Microgravity case 4.

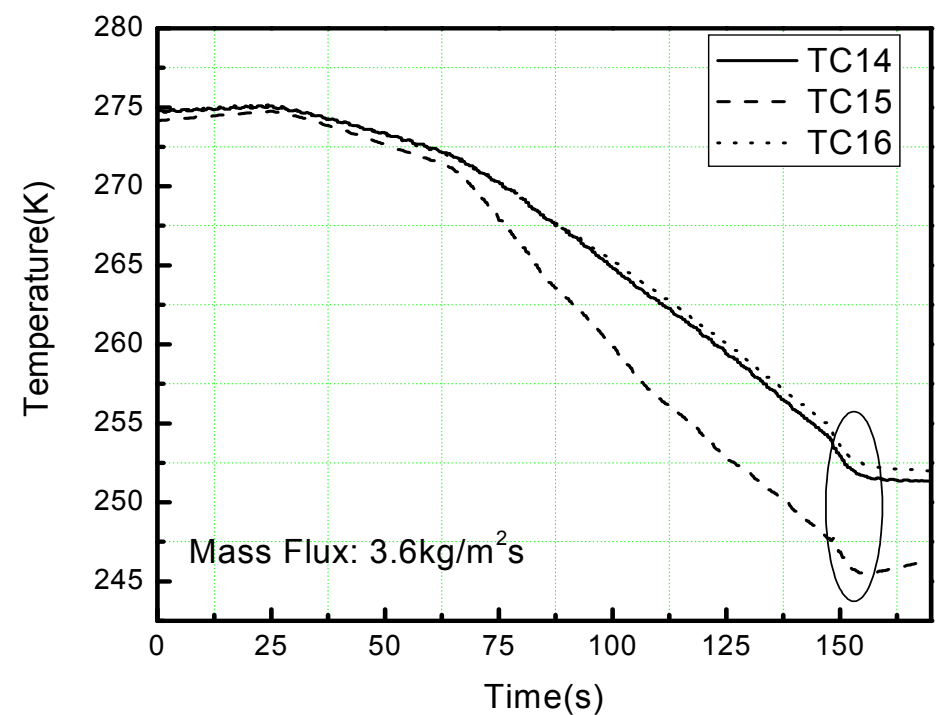

A

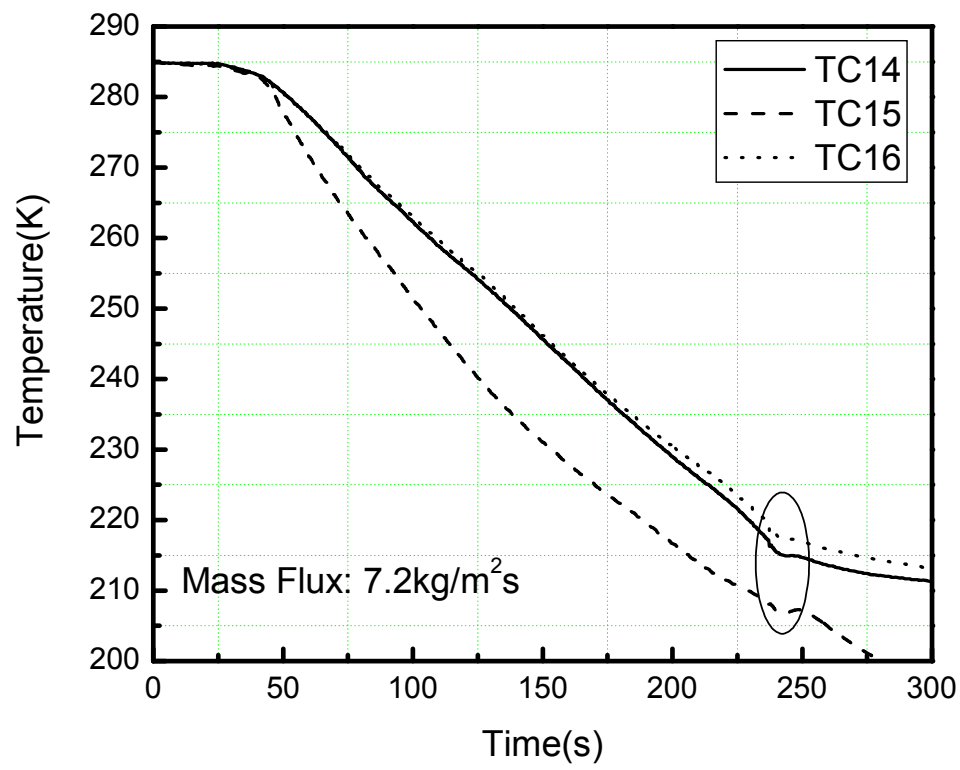

B

Fig. 17 Temperature profiles with different mass fluxes in microgravity test. A) Mass flux of $3.6 \mathrm{~kg} / \mathrm{m}^{2} \mathrm{~s}$. B) Mass flux of $7.2 \mathrm{~kg} / \mathrm{m}^{2} \mathrm{~s}$.

To examine the detail of the wall temperature response to the sudden removal of the gravity force, the temperature profiles are zoomed in. Figure 18 illustrates the typical results. It is observed that the temperature decreasing rate at the bottom wall is generally slower during the microgravity period, because the removal of the gravitational force will thicken the vapor film and reduce the film boiling heat flux. Since the top wall transfers heat mainly by convection, the gravity field is expected to have a less effect on the heat transfer at the top wall. However, as shown in Figure 15 and Figure 16, it is possible for the liquid phase to contact the top wall during the microgravity period and it results in higher heat removal rate. For the current transient experimental condition, the best way to represent the data is to calculate the averaged heat flux which is given in the following section. 


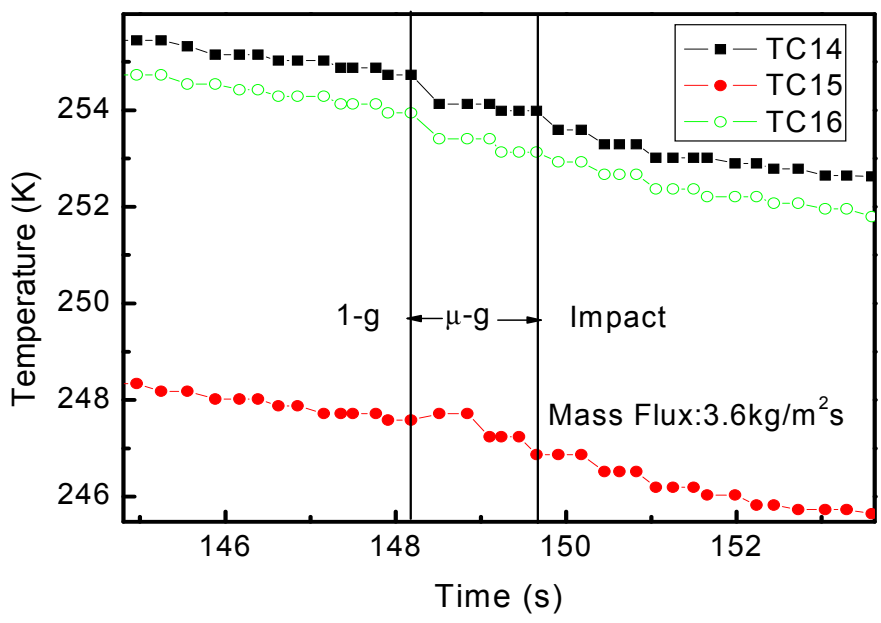

A

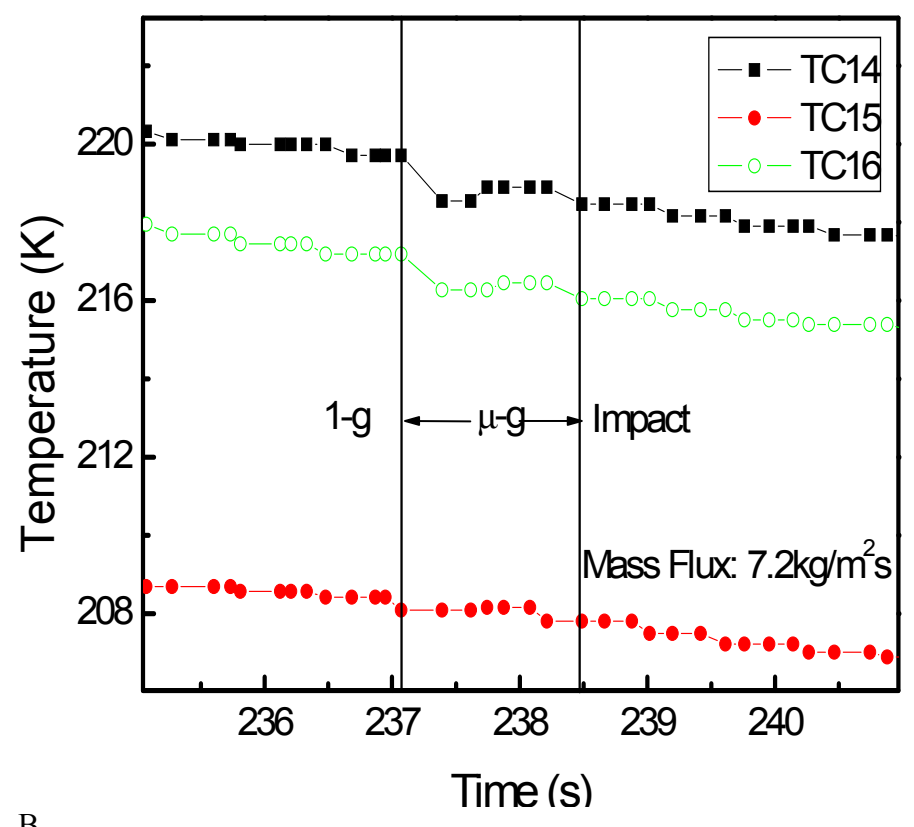

B

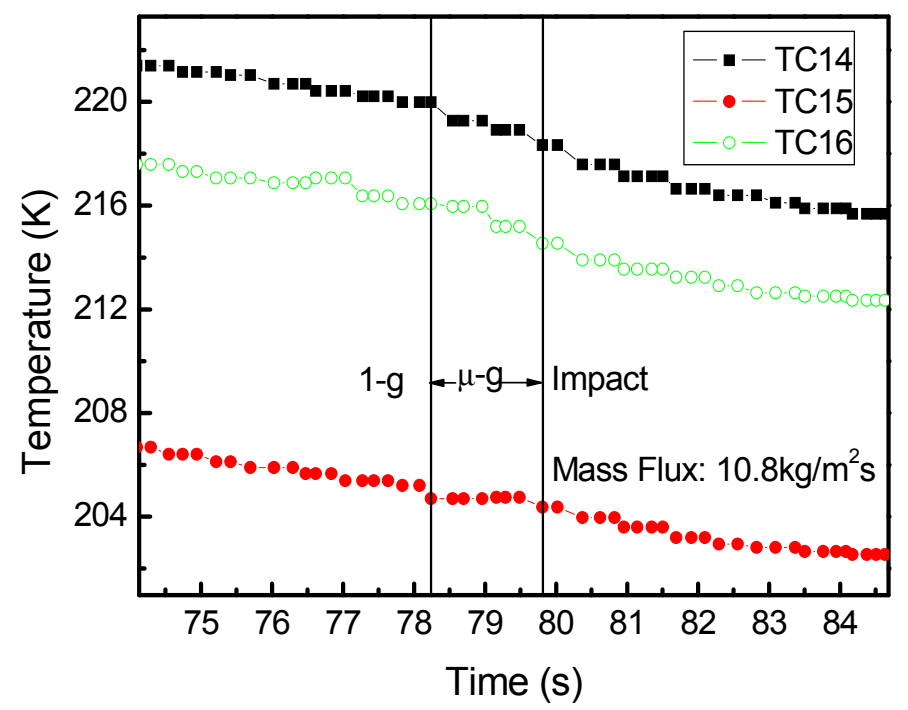

C

Fig. 18 Wall temperature response to microgravity. A) Mass flux of $3.6 \mathrm{~kg} / \mathrm{m}^{2} \mathrm{~s}$. B) Mass flux of $7.2 \mathrm{~kg} / \mathrm{m}^{2} \mathrm{~s}$. C) Mass flux of $10.8 \mathrm{~kg} / \mathrm{m}^{2} \mathrm{~s}$.

\section{Wall Heat Flux}

The gravity effect is shown in Figure 19, in which the ratio of the bottom heat flux before the drop to that during the drop is plotted for different flow rates. The heat flux at the bottom of the tube decreases under the microgravity condition and the ratio varies from the minimum of about 0.66 to about 0.90 . The result does not show a strong dependence on the wall temperature and inlet flow rate. Two runs of the quenching test performed by $\mathrm{Xu}$ (1998) reported similar ratio of 0.7 and 0.8 , however, in the work of Westbye et al. (1995), this ratio was found to be much less and ranged from 0.15 to 0.6 .

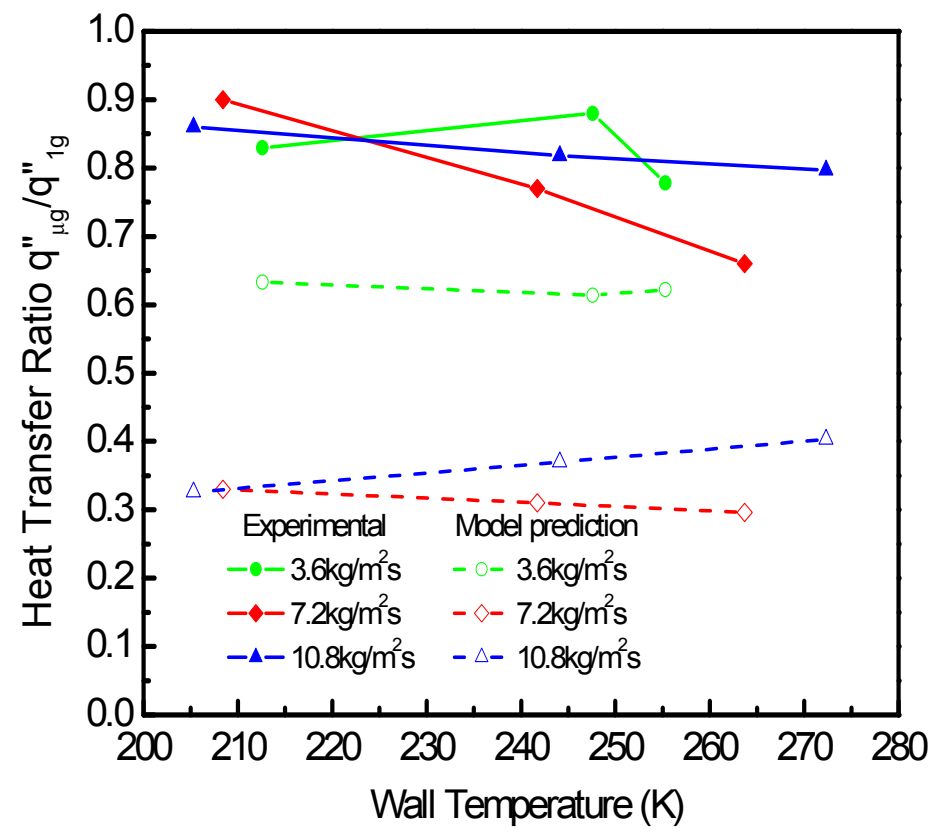

Fig. 19 Ratio of heat flux under microgravity to 1 -g condition with different flow rates and comparison with model prediction.

The bottom wall is subject to film boiling with the liquid filaments in the central core and the convection to the super heated vapor phase. For the film boiling part, the heat flux and the heat transfer coefficient are proportional to $(a / g)^{1 / 3}$ as suggested by Merte and Clark (1964). With a simple model, if we assume that the convection is not affected by the microgravity condition, the model predictions are shown by the dash lines in Figure 15. The gravity level in the model calculation is $10^{-4} \mathrm{~g}$. The model results are much scattered and significantly lower than the experimental values. This suggests that under the microgravity condition, the effect of convection may raise the heat flux, and therefore the total effect of the microgravity is less prominent than that in the pool boiling experiments.

\section{CONCLUSIONS}

The experiments show that the chilldown process can be generally divided into three regions: film boiling region, transition boiling region and nucleate boiling region, and each region is associated with different flow regime and heat transfer mechanism. After data reduction, chilldown boiling curve, which is similar to the pool boiling curve, is generated based on the wall temperature measurement. The limits between different regions of the chilldown process are clearly shown as the point of the critical heat flux (CHF) and the minimum heat flux on the chilldown boiling curve. It has been observed that the two-phase flow is dispersed in the film boiling region with liquid phase in the form of long filaments as the tube is chilled down, while the vapor phase is 
generally superheated. The heat transfer mechanism at the bottom wall is film boiling to the liquid filaments and convection to the superheated vapor phase, the upper wall transfers heat mainly by convection.

Cryogenic chilldown under microgravity condition was experimentally studied in the dispersed flow film boiling regime. During the film boiling, the bottom wall heat flux is found to decrease under microgravity condition. Under current experimental condition, the gravity effect does not show a strong dependence on wall temperature and inlet flow rate.

\section{ACKNOWLEDGEMENTS}

The support by the Andrew H. Hines, Jr./Progress Energy Endowment Fund is acknowledged.

\section{NOMENCLATURE}

$\begin{array}{ll}a & \text { Acceleration }\left[\mathrm{ms}^{-2}\right] \\ c & \text { Specific heat }\left[\mathrm{J} \mathrm{kg}^{-1} \mathrm{~K}^{-1}\right] \\ D & \text { Diameter of the flow channel }[\mathrm{m}] \\ g & \text { Gravitational acceleration constant } 9.8\left[\mathrm{~ms}^{-2}\right] \\ h & \text { Heat transfer coefficient }\left[\mathrm{Wm}^{-2} \mathrm{~K}^{-1}\right] \text {; Enthalpy }\left[\mathrm{Jkg}^{-1}\right] ; \\ & \text { Water level [ } \mathrm{m}] \\ h_{l v} & \text { latent heat of evaporation }\left[\mathrm{Jkg}^{-1} \mathrm{~K}^{-1}\right] \\ h_{l v}^{\prime} & \text { Latent heat plus vapor sensible heat content }\left[\mathrm{Jkg}^{-1} \mathrm{~K}^{-1}\right] \\ k & \left.\text { Thermal conductivity [ } \mathrm{Wm}^{-1} \mathrm{~K}^{-1}\right] \\ q^{\prime \prime} & \left.\text { Heat flux [ Wm }{ }^{-2}\right] \\ r & \text { Radius of the flow channel }[\mathrm{m}] \\ t & \text { Time [s] } \\ T & \text { Temperature [K] } \\ \Delta T_{w} & \text { wall superheat }[\mathrm{K}]\end{array}$

\section{Greek letters}

$\begin{array}{ll}\alpha & \text { Thermal diffusivity }\left[\mathrm{m}^{2} \mathrm{~s}^{-1}\right] \\ \mathcal{E} & \text { Emissivity } \\ \mu & \text { Viscosity }\left[\mathrm{kgm}^{-1} \mathrm{~s}^{-1}\right] \\ \rho & \text { Density }\left[\mathrm{kg} \mathrm{m}^{-3}\right] \\ \sigma & \text { Surface tension }\left[\mathrm{N} \mathrm{m}^{-1}\right] \\ \sigma_{B} & \text { Stefen Boltzmann constant } 5.67 \times 10^{-8}\left[\mathrm{~W} \mathrm{~m}^{-2} \mathrm{~K}^{-4}\right]\end{array}$

\section{Subscripts}

$\begin{array}{ll}\text { CHF } & \text { Critical heat flux } \\ \text { cond } & \text { Conduction } \\ \text { conv } & \text { Convection } \\ \mathrm{fb} & \text { Film boiling } \\ \mathrm{i} & \text { Interfacial; Inner } \\ 1 & \text { Liquid phase } \\ \text { min } & \text { Minimum }\end{array}$

$\begin{array}{ll}\text { o } & \text { Outer } \\ \text { rad } & \text { Radiation } \\ \text { tc } & \text { Thermocouple } \\ \text { v } & \text { Vapor phase } \\ \text { w } & \text { Wall }\end{array}$

\section{REFERENCES}

Abdul-Razzak, A., Shoukri, M., and Chan, A. M. C., 1992, "Rewetting of Horizontal Tubes," Nuclear Engineering and Design, 138, 375-388. http://dx.doi.org/10.1016/0029-5493(92)90072-4

Adham-Khodaparast, K., Xu, J. J., and Kawaji, M., 1995, "Flow Film Boiling Collapse and Surface Rewetting in Normal and Reduced Gravity Conditions," International Journal of Heat and Mass Transfer, 38, 2749-2760.

http://dx.doi.org/10.1016/0017-9310(95)00026-6

Andreani, M., and Yadigaroglu, G., 1996, "A 3-d Eulerian-Lagrangian Model of Dispersed Flow Film Boiling Including a Mechanistic Description of the Droplet Spectrum Evolution I. The ThermalHydraulic Model," International Journal of Heat and Mass Transfer, 40, 1753-1772.

http://dx.doi.org/10.1016/S0017-9310(96)00253-0

Antar, B. N., and Collins, F. G., 1997, "Flow Boiling during Quenching in Low Gravity Environment," International Journal of Microgravity Science and Technology, 3, 118-128.

http://dx.doi.org/10.1016/0094-4548(78)90048-6

Berenson, P. J., 1961, "Film-Boiling Heat Transfer from a Horizontal Surface," ASME Journal of Heat Transfer, 83, 351-358.

http://dx.doi.org/10.1115/1.3682280

Bergles, A. E., and Thompson, W. G., 1970, "The Relationship of Quench Data to Steady-State Pool Boiling Data," International Journal of Heat and Mass Transfer, 13, 55-68. http://dx.doi.org/10.1016/0017-9310(70)90024-4

Breen, B. P., and Westwater, J. W., 1962, "Effect of Diameter of Horizontal Tubes on Film Boiling Heat Transfer," Chemical Engineering Progress, 58, 67-72.

Brentari, E. G., Giarratano, P. J., and Smith, R.V., 1965, Boiling Heat Transfer for Oxygen, Nitrogen, Hydrogen, and Helium, NBS Technical Note No. 317, National Bureau of Standards.

Brentari, E. G., and Smith, R. V., 1965, "Nucleate and Film Pool Boiling Design Correlations for O2, N2, H2 and He," Advances in Cryogenic Engineering, 10, 325-341.

http://dx.doi.org/10.1115/1.3244455

Bronson, J. C., Edeskuty, F.J., Fretwell, J.H., Hammel, E.F., Keller, W.E., Meier, K.L., Schuch, A.F., and Willis, W.L., 1962, "Problems in Cool-Down of Cryogenic Systems," Advances in Cryogenic Engineering, 7, 198-205.

http://dx.doi.org/10.1007/978-1-4757-0531-7_25 
Burggraf, O. R., 1964, “An Exact Solution of Inverse Problem in Heat Conduction Theory and Application," ASME Journal of Heat Transfer, 86, 373-382.

http://dx.doi.org/10.1115/1.3688700

Burke, J. C., Byrnes, W. R., Post, A. H., and Ruccia, F. E., 1960, "Pressure Cooldown of Cryogenic Transfer Lines," Advances in Cryogenic Engineering, 4, 378-394.

http://dx.doi.org/10.1007/978-1-4757-0540-9 33

Carey, V. P., 1992, Liquid-vapor phase-change phenomena, Taylor \& Francis Press, NewYork .

Chan, A. M. C., 1995, "Stratified Flow Film Boiling inside Horizontal Tubes," ASME Journal of Heat Transfer, 117, 179-184.

http://dx.doi.org/10.1115/1.2822300

Chan, A. M. C., and Banerjee, S., 1981a, "Refilling and Rewetting of a Hot Horizontal Tube Part I: Experiment," ASME Journal of Heat Transfer, 103, 281-286.

http://dx.doi.org/10.1115/1.3244454

Chan, A. M. C., and Banerjee, S., 1981b, "Refilling and Rewetting of a Hot Horizontal Tube Part II: Structure of a Two-Fluid Model," ASME Journal of Heat Transfer, 103, 287-292.

http://dx.doi.org/10.1115/1.3244454

Chan, A. M. C., and Banerjee, S., 1981c, "Refilling and Rewetting of a Hot Horizontal Tube Part III: Application of a Two-Fluid Model to Analyze Rewetting," ASME Journal of Heat Transfer, 103, 653-659. http://dx.doi.org/10.1115/1.3244454

Chang, Y. P., 1959, "Wave Theory of Heat Transfer in Film Boiling," ASME Journal of Heat Transfer, 8, 1-12.

Chang, Y. P., and Snyder, N. W., 1960, "Heat Transfer in Saturated Boiling," Chemical Engineering Progress Symposium, 56, 25-38.

Chen, W. J., Lee, Y., and Groeneveld, D. C., 1979, "Measurement of Boiling Curves during Rewetting of a Hot Circular Duct," International Journal of Heat and Mass Transfe, 22, 973-976. http://dx.doi.org/10.1016/0017-9310(79)90039-5

Cheng, S. C., 1978, "Transition Boiling Curves Generated from Quenching Experiments using a Two Dimensional Model," Letters in Heat and Mass Transfer, 5, 391-403.

http://dx.doi.org/10.1016/0735-1933(78)90019-2

Cheng, S. C., Ng, W. W. L., and Heng, K. T., 1978, "Measurements of Bboiling Curves of Subcooled Water under Forced Convective Conditions," International Journal of Heat and Mass Transfer, 21, 1385-1392.

http://dx.doi.org/10.1016/0017-9310(78)90202-8

Cheng, S. C., and Ragheb, H., 1979, "Transition Boiling Data of Water on Inconel Surface under Forced Convective Conditions," International Journal of Multiphase Flow, 5, 281-291.

http://dx.doi.org/10.1016/0301-9322(79)90026-0

Chi, J. W. H., 1965, "Cooldown Temperatures and Cooldown Time during Mist Flow," Advances in Cryogenic Engineering, 10, 330-340. http://dx.doi.org/10.1007/978-1-4684-3108-7_40
Chi, J. W. H., and Vetere, A.M., 1964, "Two-Phase Flow during Transient Boiling of Hydrogen and Determination of Nonequilibrium Vapor Fractions," Advances in Cryogenic Engineering, 9, 243-253. http://dx.doi.org/10.1007/978-1-4757-0525-6 29

Chung, J. N., and Olafsson, S. I., 1984, "Two-Phase Droplet Flow Convective and Radiative Heat Transfer," International Journal of Heat and Mass Transfer, 27, 901-910. http://dx.doi.org/10.1016/0017-9310(84)90011-5

Dhir, V. K., Duffey R. B. and Catton I., 1981, "Quenching Studies on a Zircaloy Rod Bundle," ASME Journal of Heat Transfer, 103, 293299.

http://dx.doi.org/10.1115/1.3244456

Duffey, R. B. and Porthouse, D. T. C., 1973, "The Physics of Rewetting in Water Reactor Emergency Core Cooling," Nuclear Engineering and Design, 25, 379-394.

http://dx.doi.org/10.1016/0029-5493(73)90033-2

Ganić, E. N., Rohsenow, W. M., 1977, "Dispersed Flow Heat Transfer," Intentional Journal of Heat and Mass Transfer, 20, 855-866. http://dx.doi.org/10.1016/0017-9310(77)90115-6

Gebhart, B., Jaluria, Y., Mahajan, R.L., Sammakia, B., 1988, Buoyancy-Induced Flow and Heat Transport, Hemisphere Publishing Company.

Gungor, K.E. and Winterton, R.H.S., 1987, "Simplified General Correlation for Saturated Flow Boiling and Comparisons of Correlations with Data," Chemical Engineering Research and Design, 65, 148-156.

Hammouda, N., Groeneveld, D. C., and Cheng, S. C., 1997, "TwoFluid Modeling of Inverted Annular Film Boiling," International Journal of Heat and Mass Transfer, 40, 2655-2670. http://dx.doi.org/10.1016/S0017-9310(96)00278-5

Hsu, Y. Y., and Graham, R. W., 1963, A Visual Study of Two-Phase Flow in a Vertical Tube with Heat Addition, NASA-TN-1564.

Iloeje, O. C., Plummer, D. N., Rohsenow, W. M. and Griffith, P., 1975, "An Investigation of the Collapse and Surface Rewet in Film Boiling in Forced Vertical Flow," ASME Journal of Heat Transfer, 42, 33873407.

http://dx.doi.org/10.1115/1.3450336

Incropera, F. P., and Dewitt, D. P., 2002, Fundamentals of heat and mass transfer, 5th edition. John Wiley \& Sons, New York.

Kawaji, M., Ng, Y.S., Banerjee, S., and Yadigaroglu, G., 1985, "Reflooding with Steady and Oscillatory Injection: Part I-Flow Regimes, Void Fraction, and Heat Transfer," ASME Journal of Heat Transfer, 107, 670-678. http://dx.doi.org/10.1115/1.3247476

Klimenko, V.V., Fyodorov, M.V., and Fomichyov, Yu. A., 1989, "Channel Orientation and Geometry Influence on Heat Transfer with Two-Phase Forced Flow of Nitrogen," Cryogenics, 29, 31-36. http://dx.doi.org/10.1016/0011-2275(89)90008-8 
Kutateladze, S.S., 1952, "Heat Transfer in Condensation and Boiling," State Sci. and Tech. Pub. Of Lit. on Machinery, Moscow (Atomic Energy Commission Translation 3770, Tech. Info Service, Oak Ridge, Tennessee.)

Liao, J., 2005, Modeling Two-Phase Transport during Cryogenic Chilldown in a Pipeline, Ph.D. dissertation, University of Florida.

Lin C-S, Van Dresar, N. T., and Hasan, M. M., 1991, A Pressure Control Analysis of Cryogenic Storage Systems, NASA TM 104409.

Merte, Jr., H., and Clark, J. A., 1964, "Boiling Heat Transfer with Cryogenic Fluids at Standard, Fractional, and Near-Zero Gravity," ASME Journal of Heat Transfer, 86, 315-319.

http://dx.doi.org/10.1115/1.3688689

Noyes, R. C.,1963, “An Experimental Study of Sodium Pool Boiling Heat Transfer," ASME Journal of Heat Transfer, 85, 125-132. http://dx.doi.org/10.1115/1.3686029

Piggott, B. D. G., and Porthouse, D. T. C., 1975, "A Correlation of Rewetting Data," Nuclear Engineering and Design, 32, 171-181. http://dx.doi.org/10.1016/0029-5493(75)90128-4

Raithby, G. D., and Hollands, K. G. T., 1975, “A General Method of Obtaining Approximate Solutions to Laminar and Turbulent Free Convection Problems," Advances in Heat Transfer, 11, 265-315, Academic Press, New York.

http://dx.doi.org/10.1016/S0065-2717(08)70076-5

Seader, J. D., Miller, W. S., and Kalvinskas, L.A., 1965, Boiling heat transfer for cryogenics, NASA Contractor Report CR-243.

Shah, M. M., 1984, "Prediction of Heat Transfer during Boiling of Cryogenic Fluids Flowing in Tubes," Cryogenics, 24, 231-236. http://dx.doi.org/10.1016/0011-2275(84)90148-6

Shah, M. M. and Siddiqui, M. A., 2000, "A General Correlation for Heat Transfer during Dispersed-Flow Film Boiling in Tubes," Heat Transfer Engineering, 21, 18-32. http://dx.doi.org/10.1080/01457630050144479

Thompson, T. S., 1974, "Process of Rewetting a Hot Surface by a Falling Liquid-Film," Nuclear Engineering and Design, 31, 234-245. http://dx.doi.org/10.1016/0029-5493(75)90144-2
Van Dresar, N. T. and Siegwarth, J. D., 2001, Near-Horizontal, TwoPhase Flow Patterns of Nitrogen and Hydrogen at Low Mass and Heat Flux, NASA TP 2001-210380.

Van Dresar, N.T., Siegwarth, J.D., and Hasan, M.M., 2002, "Convective Heat Transfer Coefficients for Near-Horizontal TwoPhase Flow of Nitrogen and Hydrogen at Low Mass and Heat Flux," Cryogenics, 41, 805-811. http://dx.doi.org/10.1016/S0011-2275(01)00173-4

Velat, C., 2004, Experiments in cryogenic two phase flow, Master thesis, University of Florida.

Westbye, C. J., Kawaji, M., and Antar B.N., 1995, "Boiling Heat Transfer in the Quenching of a Hot Tube under Microgravity," AIAA Journal of Thermophysics and Heat Transfer, 9, 302-307. http://dx.doi.org/10.2514/3.660

Wright, C. C., and Walters, H. H., 1959, Single tube heat transfer tests, gaseous and liquid hydrogen, WADC Technical Report 59, 423.

Xu, J. J., 1998, Flow Boiling Heat Transfer in the Quenching of a Hot Surface under Reduced Gravity Conditions, Ph.D. dissertation, University of Toronto.

Yadigaroglu, G., Nelson, R. A., Teschendorff, V., Murao, Y., Kelly, J., and Bestion, D., 1993, "Modeling of Reflooding," Nuclear Engineering and Design, 145, 1-35. http://dx.doi.org/10.1016/0029-5493(93)90056-F

Yamanouchi, A., 1968, "Effect of Core Spray Cooling in Transient State after Loss of Coolant Accident," Journal of Nuclear Science and Technology, 5, 547-558. http://dx.doi.org/10.1080/18811248.1968.9732504

Yuan, K., 2006, Cryogenic Boiling and Two-Phase Flow Chilldown Process under Terrestrial and Microgravity Conditrions, Ph.D. dissertation, University of Florida.

Zuber, N., 1958, "On Stability of Boiling Heat Transfer," ASME Journal of Heat Transfer, 80, 711-720. http://dx.doi.org/10.1115/1.3688707

Zuber, N., 1959, Hydrodynamic aspects of boiling heat transfer, Ph.D. dissertation, UCLA. 